Article

\title{
An Analysis of the Genetic Diversity of Bread Wheat $x$ Spelt Breeding Lines in Terms of Their Resistance to Powdery Mildew and Leaf Rust
}

\author{
Klaudia Goriewa-Duba ${ }^{1, *(\mathbb{D})}$, Adrian Duba ${ }^{2}$, Elżbieta Suchowilska ${ }^{1}$ and Marian Wiwart ${ }^{1}$ (D) \\ 1 Department of Plant Breeding and Seed Production, University of Warmia and Mazury in Olsztyn, \\ pl. Łódzki 3, 10-724 Olsztyn, Poland; ela.suchowilska@uwm.edu.pl (E.S.); wiwart@uwm.edu.pl (M.W.) \\ 2 Department of Entomology, Phytopathology and Molecular Diagnostics, \\ University of Warmia and Mazury in Olsztyn, Prawocheńskiego 17, \\ 10-719 Olsztyn, Poland; adrian.duba@uwm.edu.pl \\ * Correspondence: klaudia.goriewa@uwm.edu.pl
}

Received: 1 April 2020; Accepted: 4 May 2020; Published: 7 May 2020

\begin{abstract}
The main aim of this study was to analyze the genetic diversity of breeding lines derived from bread wheat and spelt (bread wheat cvs. Zebra, Torka and Kontesa; spelt breeding lines S10-S14) in terms of their resistance to infections caused by Blumeria graminis f. sp. tritici and Puccinia triticina Eriks. The genomes of all analyzed lines harbored the markers for Pm2a, Pm4b and $P m 6$ a alleles, which confer resistance to the infection caused by B. graminis f. sp. tritici. The markers for $P m 4 c$ and $P m 4 a$ alleles were also identified in many objects. The high number of $P m$ markers was noted in the crosses Zebra $\times$ S11 and Zebra $\times$ S12 whose genomes harbored the markers for Pm2a, Pm3d, Pm4a-4c and Pm6. Most of the studied lines harbored the marker linked to the Lr10 gene, which encodes resistance to the infection caused by $P$. triticina in wheat. The analysis of the presence of markers linked to the resistance to infections caused by B. graminis $\mathrm{f}$. sp. tritici and P. triticina demonstrated that Zebra $\times$ S12 was the most promising breeding line with the highest number of markers for genes/alleles encoding resistance to powdery mildew and leaf rust. This breeding line was also highly resistant to both pathogens under field conditions.
\end{abstract}

Keywords: bread wheat; spelt; bread wheat-spelt crosses; powdery mildew; leaf rust

\section{Introduction}

Biodiversity conservation in crops, in particular wheat, is one of the greatest challenges facing cereal breeders in the 21st century [1]. Modern bread wheat (Triticum aestivum L.) varieties have to be characterized by high yields, high protein content, as well as high resistance to biotic and abiotic stressors [2]. High-yielding varieties of bread wheat could account for up to $90 \%$ of wheat grown around the world in the 21st century [3]. However, only a limited number of local varieties, many of which are closely interrelated, can be used as breeding materials, which narrows down the gene pool of bread wheat [4]. For this reason, taxa that are closely related to T. aestivum are increasingly used for the creative breeding of new varieties with desirable agronomic traits, high nutritional value, high processing suitability, as well as resistance to the most dangerous fungal pathogens [5]. Hexaploid spelt (Triticum spelta L.) is one of such taxa. It is believed that spelt evolved into bread wheat through multiple mutations [6]. There are practically no crossing barriers between the two species, which enables the production of fertile and stable hybrids that can be characterized by higher quality grain and greater resistance to pathogens than bread wheat. Allohexaploid spelt, closely related to bread wheat, has a similar genetic structure to T. aestivum. At present, spelt is produced mainly in organic farms because it has lower agronomic requirements than bread wheat and can be grown in 
areas with less favorable soil and climate conditions. Selected morphological traits of spelt, including non-free-threshing spikelets, low spike density, and genetic polymorphism of different populations contribute to its resistance to fungal pathogens $[7,8]$.

Powdery mildew and leaf rust are the most ubiquitous foliar diseases of spring wheat in Central Europe. Global food security could be compromised by fungal diseases in wheat farms, which is why efforts are being made to screen new breeding materials for sources of resistance to these diseases. Powdery mildew caused by Blumeria graminis (DC.) E.O. Speer f. sp. tritici Em. Marchali (Bgt) and leaf rust caused by Puccinia triticina Eriks. (Prt) are among the most dangerous diseases of wheat. Infections caused by B. graminis f. sp. tritici and P. triticina can decrease yields by as much as $14 \%-60 \%$ [9].

Resistant cultivars of wheat continue to attract growing interest as the most economical and environmentally-friendly approach to disease control, which eliminates fungicides and minimizes yield losses caused by fungal diseases [10]. The use of molecular markers in analyses of potential breeding materials enables rapid screening of plant genotypes.

In genetic terms, plants possess qualitative and quantitative resistance to pathogens, which is conditioned by major gene or multiple genes. In most cases, resistance to powdery mildew and leaf rust is encoded monogenically in wheat. However, pathogens can easily overcome single-gene resistance. Therefore, wheat breeders are searching for the most effective methods of combining resistance genes in the gene pyramiding process. This broad-spectrum technique is applied to increase the durability of crop resistance to plant pathogens [11]. Breeding materials have to be screened for markers linked to $P m$ and $L r$ genes, which encode resistance to infections caused by B. graminis f. sp. tritici and P. triticina, respectively. To date, more than 77 formal $P m$ genes and more than 30 temporarily designated genes (such as PmYB or PmWFJ) have been identified in 56 chromosomal loci in bread wheat [12,13]. Most Pm genes are localized on the chromosomes of A- and B-genomes (46.2\% and $35.1 \%$ of all $\mathrm{Pm}$ genes, respectively). The Pm genes mapped on chromosomes 1D-2D and 5D-7D account for $18.7 \%$ of all $\mathrm{Pm}$ genes. The mean number of powdery mildew resistance gene alleles has been determined as 3 in the A-genome, 1.19 in the B-genome, and 1.31 in the D-genome, which clearly indicates that every $\mathrm{Pm}$ locus in the A-genome of bread wheat contains a higher number of alleles than the corresponding loci in B- and D- genomes [13]. Genes encoding resistance to powdery mildew have multi-allelic sites, where selected $P m$ genes that respond differently to $B g t$ isolates are located at the same locus in different genotypes. Such genes include Pm1 (Pm1a-1e), Pm2 (Pm2a-2c, PmX3986-2, PmWFJ, PmD57-5D, PmLX66 and other), Pm3 (Pm3a-3j), Pm4 (Pm4a-4e), Pm5 (Pm5a-Pm5e) and Pm24 (Pm24a-Pm24b) [14,15]. The presence of many alleles of the $P m$ gene in the wheat genome constitutes a genetic base for increased resistance to powdery mildew. Some of the mentioned genes are considered as effective. During the evaluation of the putative resistance genes in wheat bread, other factors should be also considered, e.g., the number of $B g t$ isolates virulent to particular gene. An example is $P m 2 a$, which is believed not to be highly effective against $B g t$ isolates. Despite the above, the number of $B g t$ isolates virulent to Pm2a remained relatively low in some parts of the world [16]; thus, this allele can be used in breeding studies. The investigated in this study marker for the Pm3d allele has been identified mostly in European cultivars of bread wheat. To date, its presence has been confirmed in Nordic cultivars of spring wheat $[17,18]$, including Zebra, as well as breeding materials originating from Germany, the UK, and the Netherlands [17]. According to Li et al. [19], the Pm3d allele is gradually disappearing from bread wheat populations. The Pm4 locus is one of the most widely recognized loci of genetic resistance to powdery mildew, which exists alone or in combination with other powdery mildew resistance genes in many resistant cultivars of wheat [20]. The $P m 4 a$ resistance allele has been used in breeding efforts for several decades $[20,21]$. However, research suggests that this locus ceased to confer resistance in wheat growing areas such as Central and Eastern Europe, south-west China and the USA [21].

To date, over 80 leaf rust resistance genes have been described [22]. Most $L r$ genes are located on the short arm of chromosome 2B [23], and much fewer $L r$ genes are found on the chromosomes of the A-genome [24]. Most of these genes confer race-specific resistance. However, quick pathogen adaptation may result in the breakdown of $L r$ resistance genes [25]. The above shift the focus in 
resistance breeding from race-specific/qualitative resistance ( $R$-gene resistance) conditioned by a single large-effect gene to non-race-specific/quantitative resistance. Polygenic resistance is conditioned by many small-effect genes in the genome, which contribute to the achievement of durable resistance.

To counteract the global threat of powdery mildew and leaf rust, systematic efforts are being made to screen new breeding materials for resistance genes. Genetic similarity resulting from the same number of chromosomes $(2 n=6 x=42)$ and considerable homology between bread wheat and spelt chromosomes creates new opportunities for developing stabile and high-yielding hybrids [26]. Breeding programs require diverse genetic material as a source of genes encoding agriculturally desirable traits. Cultivars Torka and Zebra are elite wheat cultivars (E) with the highest flour strength and high protein content, whereas Kontesa is a high-yielding cultivar of quality class A [27]. In principle, such hybrids constitute valuable breeding materials, including in resistance breeding. These efforts gave rise to hybrids between spelt breeding lines and bread wheat cultivars. The relevant research is also being carried out by the Department of Plant Breeding and Seed Production of the University of Warmia and Mazury (UWM) in Olsztyn, Poland [28].

The spelt lines bred by the UWM in Olsztyn differ in morphological traits and certain agronomic traits. A cytogenetic study also revealed differences in the distribution of repetitive sequences, which could indicate that bread wheat and spelt hybrids are genetically variable [26]. The objective of this study was to evaluate the health status of bread wheat and spelt hybrids and their parental forms (three spring wheat cultivars: Torka, Zebra, and Kontesa, and five spelt lines bred by the UWM in Olsztyn: S10, S11, S12, S13 and S14) under field conditions. Selected markers linked to the genes that encode resistance to infections caused by $B$. graminis $\mathrm{f}$. sp. tritici and $P$. triticina in wheat were also applied, and their interaction effects on the severity of powdery mildew and leaf rust were determined to select the most valuable wheat-spelt lines.

\section{Materials and Methods}

The experimental material comprised 72 breeding lines representing $24 \mathrm{~F}_{7}$ and $\mathrm{F}_{8}$ generation hybrids from single crosses between T. spelta $\times$ T. aestivum and T. aestivum $\times$ T. spelta and their parental forms: spring spelt breeding lines (S10, S11, S12, S13 and S14 selected from a large group of accessions obtained from the National Center for Plant Genetic Resources in Radzików, Poland) characterized by high technological and nutritional properties, selected at the Department of Plant Breeding and Seed Production of the University of Warmia and Mazury in Olsztyn, Poland, and three spring cultivars of bread wheat: two elite cultivars: Torka and Zebra and one bread cultivar-Kontesa (Table 1). The absence of T x S13 cross was caused by significant differences in flowering dates of parental forms. Wheat lines were bulk harvested, in $\mathrm{F}_{7}$ generation classic negative selection has been applied-the plants, which differ significantly from the whole population in terms of phenotypic traits (e.g., spike shape, height etc.), were removed from further analyses.

The bread wheat cultivars have different gene pools. Cultivar Torka is slightly less resistant to leaf rust and powdery mildew than cv. Zebra and cv. Kontesa is characterized by a slightly lower technological value than previously described bread cultivars, nevertheless Kontesa has a relatively high yield making this cultivar interesting for future breeding studies. Spelt lines were previously investigated in terms of possible suitability for nutritional purposes and resistance to fungal pathogens causing FHB (Fusarium Head Blight), powdery mildew and leaf rust. The assessment of health status was conducted during field experiments. Starting the crossing, no molecular analyses were performed to confirm the presence of leaf rust and powdery mildew resistance genes. The parental spelt lines selected from genebank accessions fully meet "true spelt" criteria in terms of phenotypic traits. Three morphologically varied lines were selected under field conditions from each of the 24 groups of sister lines. 
Table 1. Breeding lines and parental forms analyzed in the study.

\begin{tabular}{|c|c|c|}
\hline Object & Origin & Breeding Line \\
\hline 1 & $\mathrm{~T} \times \mathrm{S} 10$ & $1,1^{\prime}, 1^{\prime \prime}$ \\
\hline 2 & $\mathrm{~T} \times \mathrm{S} 11$ & $2,2^{\prime}, 2^{\prime \prime}$ \\
\hline 3 & $\mathrm{~T} \times \mathrm{S} 12$ & $3,3^{\prime}, 3^{\prime \prime}$ \\
\hline 4 & $\mathrm{~T} \times \mathrm{S} 14$ & $4,4^{\prime}, 4^{\prime \prime}$ \\
\hline 5 & $\mathrm{~K} \times \mathrm{S} 10$ & $5,5^{\prime}, 5^{\prime \prime}$ \\
\hline 6 & $\mathrm{~K} \times \mathrm{S} 11$ & $6,6^{\prime}, 6^{\prime \prime}$ \\
\hline 7 & $\mathrm{~K} \times \mathrm{S} 12$ & $7,7^{\prime}, 7^{\prime \prime}$ \\
\hline 8 & $\mathrm{~K} \times \mathrm{S} 13$ & $8,8^{\prime}, 8^{\prime \prime}$ \\
\hline 9 & $\mathrm{~K} \times \mathrm{S} 14$ & $9,9^{\prime}, 9^{\prime \prime}$ \\
\hline 10 & $\mathrm{Z} \times \mathrm{S} 10$ & $10,10^{\prime}, 10^{\prime \prime}$ \\
\hline 11 & $\mathrm{Z} \times \mathrm{S} 11$ & $11,11^{\prime}, 11^{\prime \prime}$ \\
\hline 12 & $\mathrm{Z} \times \mathrm{S} 12$ & $12,12^{\prime}, 12^{\prime \prime}$ \\
\hline 13 & $\mathrm{Z} \times \mathrm{S} 13$ & $13,13^{\prime}, 13^{\prime \prime}$ \\
\hline 14 & $\mathrm{Z} \times \mathrm{S} 14$ & $14,14^{\prime}, 14^{\prime \prime}$ \\
\hline 15 & $\mathrm{~S} 10 \times \mathrm{T}$ & $15,15^{\prime}, 15^{\prime \prime}$ \\
\hline 16 & $\mathrm{~S} 11 \times \mathrm{T}$ & $16,16^{\prime}, 16^{\prime \prime}$ \\
\hline 17 & $\mathrm{~S} 12 \times \mathrm{T}$ & $17,17^{\prime}, 17^{\prime \prime}$ \\
\hline 18 & $\mathrm{~S} 13 \times \mathrm{T}$ & $18,18^{\prime}, 18^{\prime \prime}$ \\
\hline 19 & $\mathrm{~S} 14 \times \mathrm{T}$ & $19,19^{\prime}, 19^{\prime \prime}$ \\
\hline 20 & $\mathrm{~S} 10 \times \mathrm{K}$ & $20,20^{\prime}, 20^{\prime \prime}$ \\
\hline 21 & $\mathrm{~S} 11 \times \mathrm{K}$ & $21,21^{\prime}, 21^{\prime \prime}$ \\
\hline 22 & $\mathrm{~S} 12 \times \mathrm{K}$ & $22,22^{\prime}, 22^{\prime \prime}$ \\
\hline 23 & $\mathrm{~S} 13 \times \mathrm{K}$ & $23,23^{\prime}, 23^{\prime \prime}$ \\
\hline 24 & $\mathrm{~S} 14 \times \mathrm{K}$ & $24,24^{\prime}, 24^{\prime \prime}$ \\
\hline 25 & N/A & $\mathrm{T}$ \\
\hline 26 & N/A & $\mathrm{K}$ \\
\hline 27 & N/A & Z \\
\hline 28 & N/A & S10 \\
\hline 29 & N/A & S11 \\
\hline 30 & N/A & S12 \\
\hline 31 & N/A & S13 \\
\hline 32 & N/A & S14 \\
\hline
\end{tabular}

Key: T—cv. Torka, K—cv. Kontesa, Z—cv. Zebra, S10-S14—spring spelt breeding lines; abbreviations: e.g., $\mathrm{T} \times \mathrm{S} 10$ - Torka $\times \mathrm{S} 10$, etc.

\subsection{An Evaluation of the Health Status of Wheat-Spelt Breeding Lines and Their Parental Forms}

The field experiment was performed at the Agricultural Experiment Station in Bałcyny, Poland $\left(53^{\circ} 36^{\prime} \mathrm{N}\right.$ latitude, $19^{\circ} 51^{\prime} \mathrm{E}$ longitude). Spelt and wheat were grown and harvested in accordance with good agricultural practices. The field experiment was carried out in a randomized complete block design (RCBD) with three replications. Spikelets (spelt and wheat-spelt lines) or seeds (bread wheat) were sown in triplicate with $10 \times 20 \mathrm{~cm}$ spacing and were fertilized with $\mathrm{N} / \mathrm{P} / \mathrm{K}$ (nitrogen/phosphorus/potassium) $60 / 25 / 80 \mathrm{~kg} / \mathrm{ha}$ in plots with an area of $6 \mathrm{~m}^{2}$. The severity of powdery mildew and leaf rust was 
evaluated in plants naturally infected with B. graminis f. sp. tritici and P. triticina in 2017 and 2018. A minimum of 25 plants selected randomly from each object were examined in the flowering stage (BBCH 65) [29,30]. Three leaves from each replicate were collected to evaluate the disease severity based on the average percentage of affected leaf area on the scale proposed by the European and Mediterranean Plant Protection Organization [31].

\subsection{Identification of Resistance Genes}

DNA was isolated from two-week-old seedlings with the use of the Genomic Micro AX Plant Gravity kit (A\&A Biotechnology, Poland). The quantity and quality of DNA were measured with a spectrophotometer (nanoMaestro Gen, Poland) at $260 \mathrm{~nm}$ and $280 \mathrm{~nm}$ wavelength. The isolated genetic material was stored in TE buffer at $-20^{\circ} \mathrm{C}$ to prevent DNA degradation. The PCR assay involved the PCR Mix RAPID kit (A\&A Biotechnology, Poland) with the appropriate primers. The selected primers were specific for the genes encoding resistance to powdery mildew: Pm2 (Xcfd81-5D, [32]), Pm3d (Pm3d, [17]), Pm4a (Xgwm356, [33]), Pm4b (Me8/Em7-220, STS-241 and Xgwm382-125, [34]),

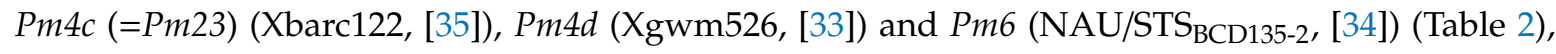
and leaf rust: Lr1 (pTAG621, [36]), Lr9 (SCS5 $\left.{ }_{550},[37]\right), \operatorname{Lr} 10$ (Lr10, [38]), Lr24 (SCS73 ${ }_{719}$, [39]), and Lr28 (SCS421570, [40]) (Table 2). Amplifications were conducted in Whatman Biometra T-personal Thermocycler. The amplification conditions for the primer sets for identifying DNA markers linked to resistance genes are listed in Table 3. Gel electrophoresis was conducted in agarose (Blirt, Poland) with ethidium bromide to visualize the amplicons. DNA bands were visualized in the Biogenet DIGIDOC gel imaging system (Biogenet, Poland).

\section{Results}

\subsection{Evaluation of Plant Health in a Field Experiment}

The health status of wheat plants was evaluated in the full flowering stage (BBCH 65) in 2017 and 2018. Symptoms of infection were expressed by the percentage of affected leaf area: none- $0 \%-1 \%$, low $-2 \%-30 \%$, high $\longrightarrow 30 \%$ ( $\mathrm{P}$ - parental forms, L-breeding lines). In most plants, symptoms of powdery mildew were not observed or were weak in the first year of the experiment. The only exceptions were lines originated from S13 x K, which were characterized by a high percentage of affected leaf area (>30\%) (Table 4$)$.

In 2018, the infections were less severe than in the previous year, which could be attributed to different weather conditions High average temperatures and low total precipitation were noted in 2018 (Figure 1). Data were provided by the Meteorological Station in Bałcyny. The infection pattern was similar in both years: cultivars Torka and Zebra and spelt lines S11-S13 showed no symptoms of B. graminis f. sp. tritici infection, and the most infected lines were 23-23" (S13 x K) (Figure 2).

Wheat leaves were more severely affected by P. triticina than B. graminis f. sp. tritici, but the noted symptoms were regarded as mild. In 2017, the parental lines of $T$. spelta did not exhibit symptoms of $P$. triticina infection. Most of the lines were also free of leaf rust symptoms in 2018. Mostly mild disease symptoms were noted in bread wheat in both years of the experiment. Leaf rust was observed in cvs. Torka, Zebra and Kontesa in 2017 and 2018. Line 18' (S13 × T) was the only wheat-spelt line characterized by high susceptibility to P. triticina infections in both years of the study (Figure 3). 


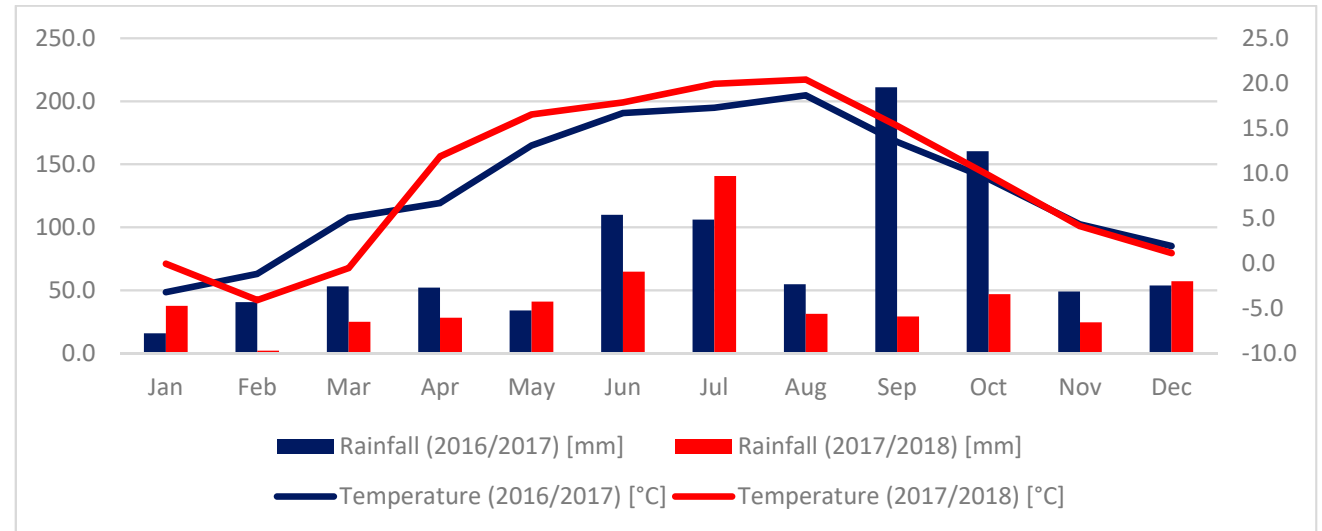

Figure 1. Weather conditions in the growing seasons of 2016/2017 and 2017/2018.

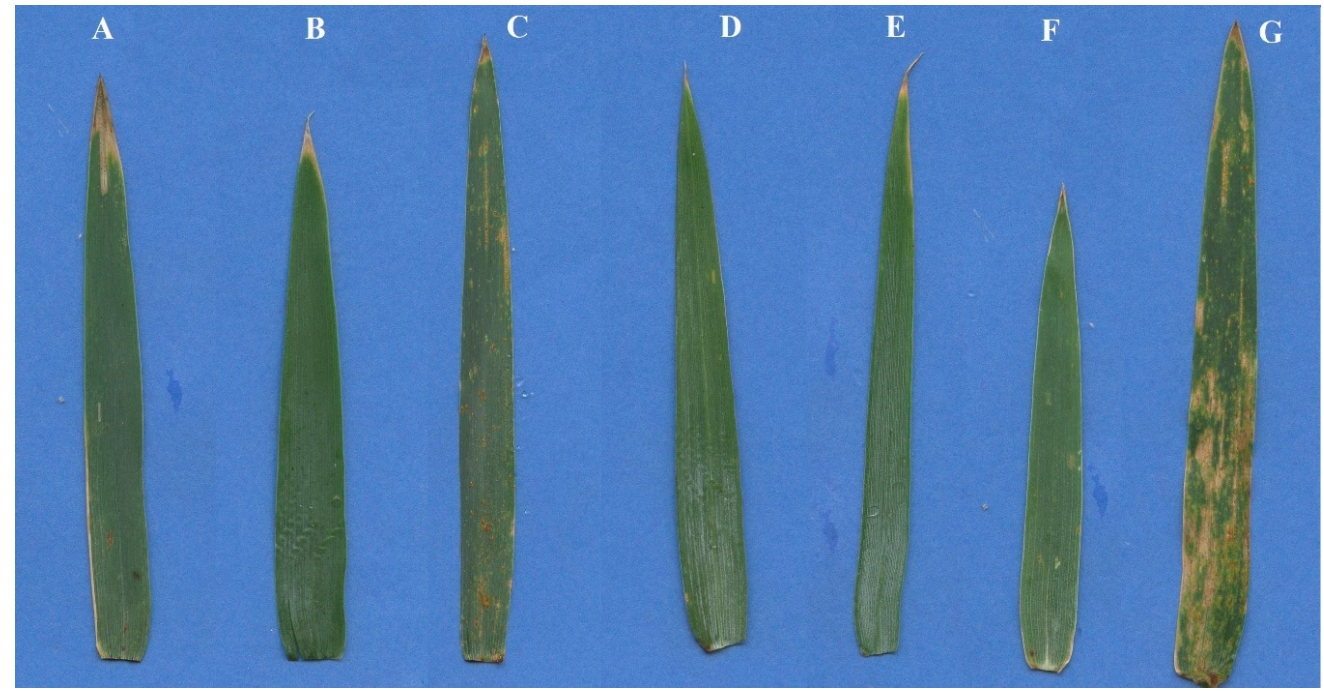

Figure 2. Symptoms of B. graminis f. sp. tritici infection on the leaves of the analyzed wheats A-cv. Torka, B-cv. Zebra, C—cv. Kontesa, D-spelt line S11, E-spelt line S12, F-spelt line S13, G-wheat $\mathrm{x}$ spelt line $23(\mathrm{~S} 13 \times \mathrm{K})$.

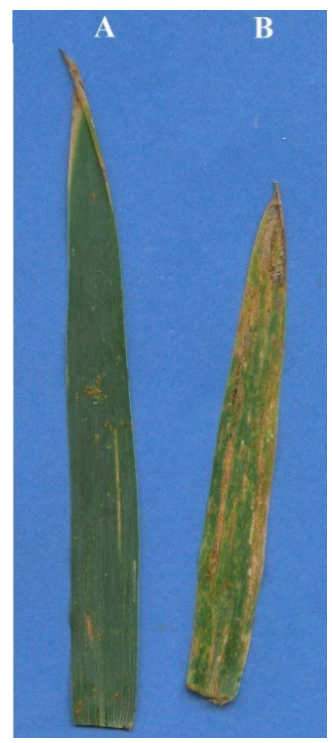

Figure 3. Symptoms of leaf rust caused by P. triticina on the leaves of bread wheat cv. Torka (A) and spelt-wheat line $18^{\prime}(\mathrm{S} 13 \times \mathrm{T})(\mathbf{B})$. 
Table 2. Primer sequences for DNA markers linked to powdery mildew and leaf rust resistance genes in wheat.

\begin{tabular}{|c|c|c|c|c|c|}
\hline Disease & Gene & Marker & Sequence $5^{\prime}->3^{\prime}(\mathrm{F})$ & Sequence $5^{\prime}->3^{\prime}(\mathrm{R})$ & Product Size $(b p)$ \\
\hline \multirow{9}{*}{$\begin{array}{l}\text { Powdery } \\
\text { mildew }\end{array}$} & Pm2 & Xcfd81-5D & ТАТССССААТССССТСТТТС & GTCAATTGTGGCTTGTCCCT & 283 \\
\hline & $P m 3 d$ & $\operatorname{Pm} 3 d$ & TGACTATTCGTGGGTGCA & GACTGCGGCACAGTTCAGC & 1109 \\
\hline & $P m 4 a$ & Xgwm356 & AGCGTTCTTGGGAATTAGAGA & CCAATCAGCCTGCAACAAC & 130 \\
\hline & \multirow{3}{*}{$P m 4 b$} & Me8/Em7-220 & TGAGTCCAAACCGGTGC & GACTGCGTACGAATTCAA & 220 \\
\hline & & STS $_{-241}$ & СTCATTCTTGTTTTACTTCCTTCAGT & GTCTCGTCTTCAGCATCCTATACA & 241 \\
\hline & & Xgwm382-125 & GTCAGATAACGCCGTCCAAT & CTACGTGCACCACCATTTTG & 125 \\
\hline & $P m 4 c$ & Xbarc122 & CCCGTGTATATCCAGGAGTG & CAGCCCTTGTGATGTGATG & 375 \\
\hline & $P m 4 d$ & Xgwm526 & CAATAGTTCTGTGAGAGCTGCG & CСAАСССАAАТАСАСАТТСТСА & $140-160 *$ \\
\hline & $P m 6$ & NAU/STS ${ }_{B C D 135-2}$ & GCTCCGAAGCAAGAGAAGAA & TCTGCTGGTCCTCTGATGTG & 135 \\
\hline \multirow{5}{*}{ Leaf rust } & Lr1 & pTAG621 & GGGTCACGTACTACTATA & CCTTGCCAGCCCAAAAG & 560 \\
\hline & $\operatorname{Lr} 9$ & SCS5 $_{550}$ & TGCGCCCTTCAAAGGAAG & TGCGCCCTTCTGAACTGTAT & 550 \\
\hline & Lr10 & Lr10 & GTGTAATGCATGCAGGTTCC & AGGTGTGAGTGAGTTATG TT & 310 \\
\hline & Lr24 & SCS73 $_{719}$ & TCGTCCAGATCAGAATGTG & CTCGTCGATTAGCAGTGAG & 719 \\
\hline & $\operatorname{Lr} 28$ & SCS$_{2} 21_{570}$ & ACAAGGTAAGTCTCCAACCA & AGTCGACCGAGATTTTAACC & 570 \\
\hline
\end{tabular}


Table 3. Amplification conditions for primer sets for identifying DNA markers linked to powdery mildew and leaf rust resistance genes.

\begin{tabular}{|c|c|c|c|}
\hline Disease & Gene & Marker & Cycle Conditions \\
\hline \multirow{9}{*}{ Powdery mildew } & $P m 2$ & Xcfd81-5D & $94{ }^{\circ} \mathrm{C}-5 \mathrm{~min} ; 35$ cycles $\left(94^{\circ} \mathrm{C}-30 \mathrm{~s} ; 60^{\circ} \mathrm{C}-30 \mathrm{~s} ; 72{ }^{\circ} \mathrm{C}-1 \mathrm{~min}\right) ; 72^{\circ} \mathrm{C}-10 \mathrm{~min}$ \\
\hline & $\operatorname{Pm} 3 d$ & $\operatorname{Pm} 3 d$ & $94{ }^{\circ} \mathrm{C}-3 \mathrm{~min} ; 35$ cycles $\left(94{ }^{\circ} \mathrm{C}-1 \mathrm{~min} ; 58^{\circ} \mathrm{C}-1 \mathrm{~min} ; 72^{\circ} \mathrm{C}-1 \mathrm{~min}\right) ; 72^{\circ} \mathrm{C}-5 \mathrm{~min}$ \\
\hline & $P m 4 a$ & Xgwm356 & $94{ }^{\circ} \mathrm{C}-3 \mathrm{~min} ; 45$ cycles $\left(94^{\circ} \mathrm{C}-1 \mathrm{~min} ; 55^{\circ} \mathrm{C}-1 \mathrm{~min} ; 72^{\circ} \mathrm{C}-2 \mathrm{~min}\right) ; 72^{\circ} \mathrm{C}-10 \mathrm{~min}$ \\
\hline & \multirow{3}{*}{$P m 4 b$} & Me8/Em7-220 & $94^{\circ} \mathrm{C}-3 \mathrm{~min} ; 35$ cycles $\left(94^{\circ} \mathrm{C}-40 \mathrm{~s} ; 50^{\circ} \mathrm{C}-1 \mathrm{~min} ; 72^{\circ} \mathrm{C}-1 \mathrm{~min}\right) ; 72^{\circ} \mathrm{C}-5 \mathrm{~min}$ \\
\hline & & STS $_{-241}$ & $94{ }^{\circ} \mathrm{C}-3 \mathrm{~min} ; 35$ cycles $\left(94^{\circ} \mathrm{C}-40 \mathrm{~s} ; 50^{\circ} \mathrm{C}-1 \mathrm{~min} ; 72^{\circ} \mathrm{C}-1 \mathrm{~min}\right) ; 7{ }^{\circ} \mathrm{C}-5 \mathrm{~min}$ \\
\hline & & Xgwm382-125 & $94^{\circ} \mathrm{C}-3 \mathrm{~min} ; 35$ cycles $\left(94^{\circ} \mathrm{C}-40 \mathrm{~s} ; 60^{\circ} \mathrm{C}-1 \mathrm{~min} ; 72^{\circ} \mathrm{C}-1 \mathrm{~min}\right) ; 72^{\circ} \mathrm{C}-5 \mathrm{~min}$ \\
\hline & $\operatorname{Pm} 4 c$ & Xbarc122 & $94{ }^{\circ} \mathrm{C}-3 \mathrm{~min} ; 35$ cycles $\left(94^{\circ} \mathrm{C}-40 \mathrm{~s} ; 52^{\circ} \mathrm{C}-1 \mathrm{~min} ; 72^{\circ} \mathrm{C}-1 \mathrm{~min}\right) ; 72{ }^{\circ} \mathrm{C}-5 \mathrm{~min}$ \\
\hline & $P m 4 d$ & Xgwm526 & $94{ }^{\circ} \mathrm{C}-3 \mathrm{~min} ; 45$ cycles $\left(94{ }^{\circ} \mathrm{C}-1 \mathrm{~min} ; 55^{\circ} \mathrm{C}-1 \mathrm{~min} ; 72{ }^{\circ} \mathrm{C}-2 \mathrm{~min}\right) ; 72{ }^{\circ} \mathrm{C}-10 \mathrm{~min}$ \\
\hline & $P m 6$ & NAU/STS $\mathrm{BCD}_{\mathrm{B} 135-2}$ & $94{ }^{\circ} \mathrm{C}-4 \mathrm{~min} ; 31$ cycles $\left(94^{\circ} \mathrm{C}-30 \mathrm{~s} ; 55^{\circ} \mathrm{C}-1 \mathrm{~min} ; 72^{\circ} \mathrm{C}-1 \mathrm{~min}\right) ; 72^{\circ} \mathrm{C}-1 \mathrm{~min}$ \\
\hline \multirow{5}{*}{ Leaf rust } & Lr1 & pTAG621 & $94{ }^{\circ} \mathrm{C}-5 \mathrm{~min} ; 30$ cycles $\left(94^{\circ} \mathrm{C}-1 \mathrm{~min} ; 55^{\circ} \mathrm{C}-1 \mathrm{~min} ; 72^{\circ} \mathrm{C}-2 \mathrm{~min}\right) ; 72^{\circ} \mathrm{C}-10 \mathrm{~min}$ \\
\hline & Lr9 & SCS5 $_{550}$ & $94^{\circ} \mathrm{C}-2 \mathrm{~min} ; 30$ cycles $\left(94^{\circ} \mathrm{C}-1 \mathrm{~min} ; 60^{\circ} \mathrm{C}-1 \mathrm{~min} ; 72^{\circ} \mathrm{C}-1 \mathrm{~min}\right) ; 72^{\circ} \mathrm{C}-7 \mathrm{~min}$ \\
\hline & Lr10 & Lr10 & $94{ }^{\circ} \mathrm{C}-3 \mathrm{~min} ; 35$ cycles $\left(94^{\circ} \mathrm{C}-45 \mathrm{~s} ; 57^{\circ} \mathrm{C}-45 \mathrm{~s} ; 72^{\circ} \mathrm{C}-30 \mathrm{~s}\right) ; 72{ }^{\circ} \mathrm{C}-3 \mathrm{~min}$ \\
\hline & $\operatorname{Lr} 24$ & $\mathrm{SCS}_{71} 719$ & $94{ }^{\circ} \mathrm{C}-2 \mathrm{~min} ; 35$ cycles $\left(94{ }^{\circ} \mathrm{C}-1 \mathrm{~min} ; 55^{\circ} \mathrm{C}-1 \mathrm{~min} ; 72{ }^{\circ} \mathrm{C}-1 \mathrm{~min}\right) ; 72{ }^{\circ} \mathrm{C}-7 \mathrm{~min}$ \\
\hline & $\operatorname{Lr} 28$ & SCS421 570 & $94{ }^{\circ} \mathrm{C}-2 \mathrm{~min} ; 35$ cycles $\left(94^{\circ} \mathrm{C}-1 \mathrm{~min} ; 60^{\circ} \mathrm{C}-1 \mathrm{~min} ; 72{ }^{\circ} \mathrm{C}-1 \mathrm{~min}\right) ; 72{ }^{\circ} \mathrm{C}-5 \mathrm{~min}$ \\
\hline
\end{tabular}


Table 4. The health status of the investigated wheat accessions in two experimental years (2017 and 2018).

\begin{tabular}{|c|c|c|c|c|c|c|c|c|c|c|}
\hline \multirow[b]{3}{*}{ Object } & \multirow[b]{3}{*}{ Origin } & \multirow[b]{3}{*}{ Breeding Line } & \multicolumn{4}{|c|}{ Powdery Mildew } & \multicolumn{4}{|c|}{ Leaf Rust } \\
\hline & & & \multicolumn{2}{|r|}{2017} & \multicolumn{2}{|r|}{2018} & \multicolumn{2}{|r|}{2017} & \multicolumn{2}{|r|}{2018} \\
\hline & & & Category & Average Score & Category & Average Score & Category & Average Score & Category & Average Score \\
\hline \multirow{3}{*}{1} & \multirow{3}{*}{$\mathrm{T} \times \mathrm{S} 10$} & 1 & \multirow{3}{*}{ None } & $0 \%$ & \multirow{3}{*}{ None } & $0 \%$ & \multirow{3}{*}{ None } & $0 \%$ & \multirow{3}{*}{ Low } & $5 \%$ \\
\hline & & $1^{\prime}$ & & $1 \%$ & & $1 \%$ & & $1 \%$ & & $10 \%$ \\
\hline & & $1^{\prime \prime}$ & & $0 \%$ & & $1 \%$ & & $1 \%$ & & $10 \%$ \\
\hline \multirow{3}{*}{2} & \multirow{3}{*}{$\mathrm{T} \times \mathrm{S} 11$} & 2 & \multirow{3}{*}{ None } & $0 \%$ & \multirow{3}{*}{ None } & $0 \%$ & \multirow{3}{*}{ None } & $0 \%$ & \multirow{3}{*}{ Low } & $5 \%$ \\
\hline & & $2^{\prime}$ & & $0 \%$ & & $0 \%$ & & $0 \%$ & & $5 \%$ \\
\hline & & $2 "$ & & $0 \%$ & & $0 \%$ & & $0 \%$ & & $10 \%$ \\
\hline \multirow{3}{*}{3} & \multirow{3}{*}{$\mathrm{T} \times \mathrm{S} 12$} & 3 & \multirow{3}{*}{ None } & $0 \%$ & \multirow{3}{*}{ None } & $1 \%$ & Low & $10 \%$ & \multirow{3}{*}{ Low } & $10 \%$ \\
\hline & & $3^{\prime}$ & & $0 \%$ & & $0 \%$ & None & $0 \%$ & & $15 \%$ \\
\hline & & $3 "$ & & $0 \%$ & & $0 \%$ & None & $0 \%$ & & $10 \%$ \\
\hline \multirow{3}{*}{4} & \multirow{3}{*}{$\mathrm{T} \times \mathrm{S} 14$} & 4 & \multirow{3}{*}{ None } & $1 \%$ & \multirow{3}{*}{ None } & $0 \%$ & \multirow{3}{*}{ None } & $1 \%$ & \multirow{3}{*}{ Low } & $5 \%$ \\
\hline & & $4^{\prime}$ & & $1 \%$ & & $1 \%$ & & $1 \%$ & & $5 \%$ \\
\hline & & $4^{\prime \prime}$ & & $0 \%$ & & $0 \%$ & & $1 \%$ & & $5 \%$ \\
\hline & & 5 & & $0 \%$ & & $0 \%$ & Low & $5 \%$ & & $0 \%$ \\
\hline 5 & $\mathrm{~K} \times \mathrm{S} 10$ & $5^{\prime}$ & None & $0 \%$ & None & $0 \%$ & None & $1 \%$ & None & $1 \%$ \\
\hline & & $5^{\prime \prime}$ & & $0 \%$ & & $0 \%$ & None & $0 \%$ & & $0 \%$ \\
\hline & & 6 & & $0 \%$ & & $0 \%$ & None & $1 \%$ & & $1 \%$ \\
\hline 6 & $\mathrm{~K} \times \mathrm{S} 11$ & $6^{\prime}$ & None & $0 \%$ & None & $0 \%$ & Low & $10 \%$ & None & $1 \%$ \\
\hline & & $6^{\prime \prime}$ & & $0 \%$ & & $1 \%$ & None & $1 \%$ & & $0 \%$ \\
\hline & & 7 & None & $0 \%$ & & $0 \%$ & None & $1 \%$ & & $0 \%$ \\
\hline 7 & $\mathrm{~K} \times \mathrm{S} 12$ & $7^{\prime}$ & Low & $10 \%$ & None & $0 \%$ & None & $1 \%$ & None & $0 \%$ \\
\hline & & $7^{\prime \prime}$ & Low & $10 \%$ & & $0 \%$ & Low & $5 \%$ & & $0 \%$ \\
\hline
\end{tabular}


Table 4. Cont

\begin{tabular}{|c|c|c|c|c|c|c|c|c|c|c|}
\hline \multirow[b]{3}{*}{ Object } & \multirow[b]{3}{*}{ Origin } & \multirow[b]{3}{*}{ Breeding Line } & \multicolumn{4}{|c|}{ Powdery Mildew } & \multicolumn{4}{|c|}{ Leaf Rust } \\
\hline & & & \multicolumn{2}{|r|}{2017} & \multicolumn{2}{|r|}{2018} & \multicolumn{2}{|r|}{2017} & \multicolumn{2}{|r|}{2018} \\
\hline & & & Category & Average Score & Category & Average Score & Category & Average Score & Category & Average Score \\
\hline \multirow{3}{*}{8} & \multirow{3}{*}{$\mathrm{K} \times \mathrm{S} 13$} & 8 & \multirow{3}{*}{ None } & $0 \%$ & \multirow{3}{*}{ None } & $0 \%$ & None & $0 \%$ & \multirow{3}{*}{ None } & $0 \%$ \\
\hline & & $8^{\prime}$ & & $1 \%$ & & $0 \%$ & Low & $10 \%$ & & $0 \%$ \\
\hline & & $8^{\prime \prime}$ & & $0 \%$ & & $1 \%$ & Low & $5 \%$ & & $0 \%$ \\
\hline \multirow{3}{*}{9} & \multirow{3}{*}{$\mathrm{K} \times \mathrm{S} 14$} & 9 & \multirow{3}{*}{ None } & $0 \%$ & \multirow{3}{*}{ None } & $0 \%$ & None & $0 \%$ & Low & $5 \%$ \\
\hline & & $9^{\prime}$ & & $1 \%$ & & $0 \%$ & None & $0 \%$ & None & $0 \%$ \\
\hline & & $9 "$ & & $1 \%$ & & $0 \%$ & High & $35 \%$ & Low & $15 \%$ \\
\hline \multirow{3}{*}{10} & \multirow{3}{*}{$\mathrm{Z} \times \mathrm{S} 10$} & 10 & \multirow{3}{*}{ None } & $0 \%$ & \multirow{3}{*}{ None } & $0 \%$ & \multirow{3}{*}{ Low } & $5 \%$ & \multirow{3}{*}{ None } & $0 \%$ \\
\hline & & $10^{\prime}$ & & $0 \%$ & & $0 \%$ & & $10 \%$ & & $0 \%$ \\
\hline & & $10^{\prime \prime}$ & & $0 \%$ & & $0 \%$ & & $10 \%$ & & $0 \%$ \\
\hline \multirow{3}{*}{11} & \multirow{3}{*}{$\mathrm{Z} \times \mathrm{S} 11$} & 11 & \multirow{3}{*}{ None } & $0 \%$ & \multirow{3}{*}{ None } & $0 \%$ & \multirow{3}{*}{ Low } & $5 \%$ & \multirow{3}{*}{ None } & $1 \%$ \\
\hline & & $11^{\prime}$ & & $1 \%$ & & $0 \%$ & & $5 \%$ & & $1 \%$ \\
\hline & & $11^{\prime \prime}$ & & $0 \%$ & & $0 \%$ & & $5 \%$ & & $1 \%$ \\
\hline \multirow{3}{*}{12} & \multirow{3}{*}{$\mathrm{Z} \times \mathrm{S} 12$} & 12 & & $0 \%$ & None & $0 \%$ & & $5 \%$ & & $0 \%$ \\
\hline & & $12^{\prime}$ & None & $0 \%$ & Low & $10 \%$ & Low & $5 \%$ & None & $0 \%$ \\
\hline & & $12^{\prime \prime}$ & & $0 \%$ & None & $1 \%$ & & $5 \%$ & & $1 \%$ \\
\hline & & 13 & & $0 \%$ & & $0 \%$ & & $0 \%$ & Low & $10 \%$ \\
\hline 13 & $\mathrm{Z} \times \mathrm{S} 13$ & $13^{\prime}$ & None & $0 \%$ & None & $0 \%$ & None & $0 \%$ & Low & $10 \%$ \\
\hline & & $13^{\prime \prime}$ & & $1 \%$ & & $0 \%$ & & $1 \%$ & None & $0 \%$ \\
\hline & & 14 & & $0 \%$ & & $0 \%$ & & $0 \%$ & & $1 \%$ \\
\hline 14 & $\mathrm{Z} \times \mathrm{S} 14$ & $14^{\prime}$ & None & $1 \%$ & None & $1 \%$ & None & $0 \%$ & None & $0 \%$ \\
\hline & & $14^{\prime \prime}$ & & $0 \%$ & & $1 \%$ & & $0 \%$ & & $1 \%$ \\
\hline
\end{tabular}


Table 4. Cont

\begin{tabular}{|c|c|c|c|c|c|c|c|c|c|c|}
\hline \multirow[b]{3}{*}{ Object } & \multirow[b]{3}{*}{ Origin } & \multirow[b]{3}{*}{ Breeding Line } & \multicolumn{4}{|c|}{ Powdery Mildew } & \multicolumn{4}{|c|}{ Leaf Rust } \\
\hline & & & \multicolumn{2}{|r|}{2017} & \multicolumn{2}{|r|}{2018} & \multicolumn{2}{|r|}{2017} & \multicolumn{2}{|r|}{2018} \\
\hline & & & Category & Average Score & Category & Average Score & Category & Average Score & Category & Average Score \\
\hline \multirow{3}{*}{15} & \multirow{3}{*}{$\mathrm{S} 10 \times \mathrm{T}$} & 15 & \multirow{3}{*}{ None } & $0 \%$ & Low & $10 \%$ & \multirow{3}{*}{ None } & $0 \%$ & \multirow{3}{*}{ None } & $0 \%$ \\
\hline & & $15^{\prime}$ & & $0 \%$ & Low & $5 \%$ & & $1 \%$ & & $0 \%$ \\
\hline & & $15^{\prime \prime}$ & & $0 \%$ & None & $0 \%$ & & $0 \%$ & & $1 \%$ \\
\hline \multirow{3}{*}{16} & \multirow{3}{*}{$\mathrm{S} 11 \times \mathrm{T}$} & 16 & \multirow{3}{*}{ None } & $0 \%$ & \multirow{3}{*}{ None } & $1 \%$ & \multirow{3}{*}{ None } & $1 \%$ & \multirow{3}{*}{ None } & $0 \%$ \\
\hline & & $16^{\prime}$ & & $1 \%$ & & $0 \%$ & & $1 \%$ & & $1 \%$ \\
\hline & & $16^{\prime \prime}$ & & $0 \%$ & & $0 \%$ & & $1 \%$ & & $1 \%$ \\
\hline \multirow{3}{*}{17} & \multirow{3}{*}{$\mathrm{S} 12 \times \mathrm{T}$} & 17 & \multirow{3}{*}{ None } & $0 \%$ & \multirow{3}{*}{ None } & $0 \%$ & \multirow{3}{*}{ None } & $1 \%$ & \multirow{3}{*}{ None } & $0 \%$ \\
\hline & & $17^{\prime}$ & & $0 \%$ & & $1 \%$ & & $0 \%$ & & $0 \%$ \\
\hline & & $17^{\prime \prime}$ & & $0 \%$ & & $0 \%$ & & $0 \%$ & & $1 \%$ \\
\hline \multirow{3}{*}{18} & \multirow{3}{*}{$\mathrm{S} 13 \times \mathrm{T}$} & 18 & \multirow{3}{*}{ Low } & $5 \%$ & \multirow{3}{*}{ None } & $1 \%$ & None & $1 \%$ & None & $1 \%$ \\
\hline & & $18^{\prime}$ & & $5 \%$ & & $1 \%$ & High & $35 \%$ & High & $60 \%$ \\
\hline & & $18^{\prime \prime}$ & & $10 \%$ & & $1 \%$ & None & $1 \%$ & Low & $10 \%$ \\
\hline \multirow{3}{*}{19} & \multirow{3}{*}{$\mathrm{S} 14 \times \mathrm{T}$} & 19 & & $10 \%$ & & $0 \%$ & None & $0 \%$ & & $10 \%$ \\
\hline & & $19^{\prime}$ & Low & $15 \%$ & None & $1 \%$ & Low & $5 \%$ & Low & $15 \%$ \\
\hline & & $19^{\prime \prime}$ & & $10 \%$ & & $1 \%$ & None & $1 \%$ & & $5 \%$ \\
\hline & & 20 & & $5 \%$ & & $1 \%$ & & $0 \%$ & & $0 \%$ \\
\hline 20 & $\mathrm{~S} 10 \times \mathrm{K}$ & $20^{\prime}$ & Low & $5 \%$ & None & $1 \%$ & None & $1 \%$ & None & $0 \%$ \\
\hline & & $20^{\prime \prime}$ & & $5 \%$ & & $1 \%$ & & $1 \%$ & & $1 \%$ \\
\hline & & 21 & & $0 \%$ & & $0 \%$ & & $1 \%$ & & $1 \%$ \\
\hline 21 & S11×K & $21^{\prime}$ & None & $0 \%$ & None & $1 \%$ & None & $1 \%$ & None & $1 \%$ \\
\hline & & $21^{\prime \prime}$ & & $0 \%$ & & $0 \%$ & & $1 \%$ & & $1 \%$ \\
\hline
\end{tabular}


Table 4. Cont.

\begin{tabular}{|c|c|c|c|c|c|c|c|c|c|c|}
\hline \multirow[b]{3}{*}{ Object } & \multirow[b]{3}{*}{ Origin } & \multirow[b]{3}{*}{ Breeding Line } & \multicolumn{4}{|c|}{ Powdery Mildew } & \multicolumn{4}{|c|}{ Leaf Rust } \\
\hline & & & \multicolumn{2}{|r|}{2017} & \multicolumn{2}{|r|}{2018} & \multicolumn{2}{|r|}{2017} & \multicolumn{2}{|r|}{2018} \\
\hline & & & Category & Average Score & Category & Average Score & Category & Average Score & Category & Average Score \\
\hline \multirow{3}{*}{22} & \multirow{3}{*}{$\mathrm{S} 12 \times \mathrm{K}$} & 22 & \multirow{3}{*}{ None } & $0 \%$ & \multirow{3}{*}{ None } & $0 \%$ & Low & $5 \%$ & \multirow{3}{*}{ None } & $1 \%$ \\
\hline & & $22^{\prime}$ & & $1 \%$ & & $0 \%$ & None & $0 \%$ & & $1 \%$ \\
\hline & & $22 "$ & & $0 \%$ & & $1 \%$ & Low & $10 \%$ & & $1 \%$ \\
\hline \multirow{3}{*}{23} & \multirow{3}{*}{$\mathrm{S} 13 \times \mathrm{K}$} & 23 & \multirow{3}{*}{ High } & $40 \%$ & \multirow{3}{*}{ Low } & $5 \%$ & \multirow{3}{*}{ High } & $30 \%$ & \multirow{3}{*}{ Low } & $15 \%$ \\
\hline & & $23^{\prime}$ & & $35 \%$ & & $15 \%$ & & $40 \%$ & & $15 \%$ \\
\hline & & $23^{\prime \prime}$ & & $40 \%$ & & $5 \%$ & & $35 \%$ & & $20 \%$ \\
\hline \multirow{3}{*}{24} & \multirow{3}{*}{$\mathrm{S} 14 \times \mathrm{K}$} & 24 & \multirow{3}{*}{ None } & $1 \%$ & \multirow{3}{*}{ Low } & $5 \%$ & High & $30 \%$ & Low & $10 \%$ \\
\hline & & $24^{\prime}$ & & $0 \%$ & & $15 \%$ & None & $1 \%$ & None & $1 \%$ \\
\hline & & $24^{\prime \prime}$ & & $0 \%$ & & $20 \%$ & None & $1 \%$ & None & $1 \%$ \\
\hline 25 & \multirow{8}{*}{ N/A } & $\mathrm{T}$ & None & $1 \%$ & None & $1 \%$ & High & $30 \%$ & Low & $5 \%$ \\
\hline 26 & & $\mathrm{Z}$ & None & $0 \%$ & None & $0 \%$ & Low & $5 \%$ & Low & $10 \%$ \\
\hline 27 & & $\mathrm{~K}$ & Low & $10 \%$ & Low & $5 \%$ & Low & $10 \%$ & Low & $15 \%$ \\
\hline 28 & & $\mathrm{~S} 10$ & Low & $10 \%$ & None & $0 \%$ & None & $0 \%$ & None & $0 \%$ \\
\hline 29 & & S11 & None & $0 \%$ & None & $0 \%$ & None & $0 \%$ & None & $0 \%$ \\
\hline 30 & & S12 & None & $0 \%$ & None & $0 \%$ & None & $0 \%$ & None & $0 \%$ \\
\hline 31 & & $\mathrm{~S} 13$ & None & $0 \%$ & None & $0 \%$ & None & $0 \%$ & Low & $10 \%$ \\
\hline 32 & & S14 & Low & $15 \%$ & None & $0 \%$ & None & $0 \%$ & None & $0 \%$ \\
\hline
\end{tabular}




\subsection{Identification of Pm Resistance Genes}

The amplification products of the following markers were identified in the electropherograms of the studied breeding lines and their parental forms: $P m 2 a$ allele, $P m 3 d$ allele, $P m 4 a$ allele, three markers for the $P m 4 b$ allele, $P m 4 c$ allele, and $P m 6$ gene (Figure 4). A PCR product with a size of $140-160 \mathrm{bp}$ linked to the Pm4d allele (Figures 5 and 6) was not observed in any of the studied forms. An analysis of wheat-spelt lines revealed the highest number of markers linked to $P m$ genes in lines Z $\times$ S11 (line $11^{\prime}$ ) and Z $\times$ S12 (line 12), where the presence of markers linked to Pm2a, Pm3d, Pm4a-4c, and Pm6 genes was confirmed (Figure 6).

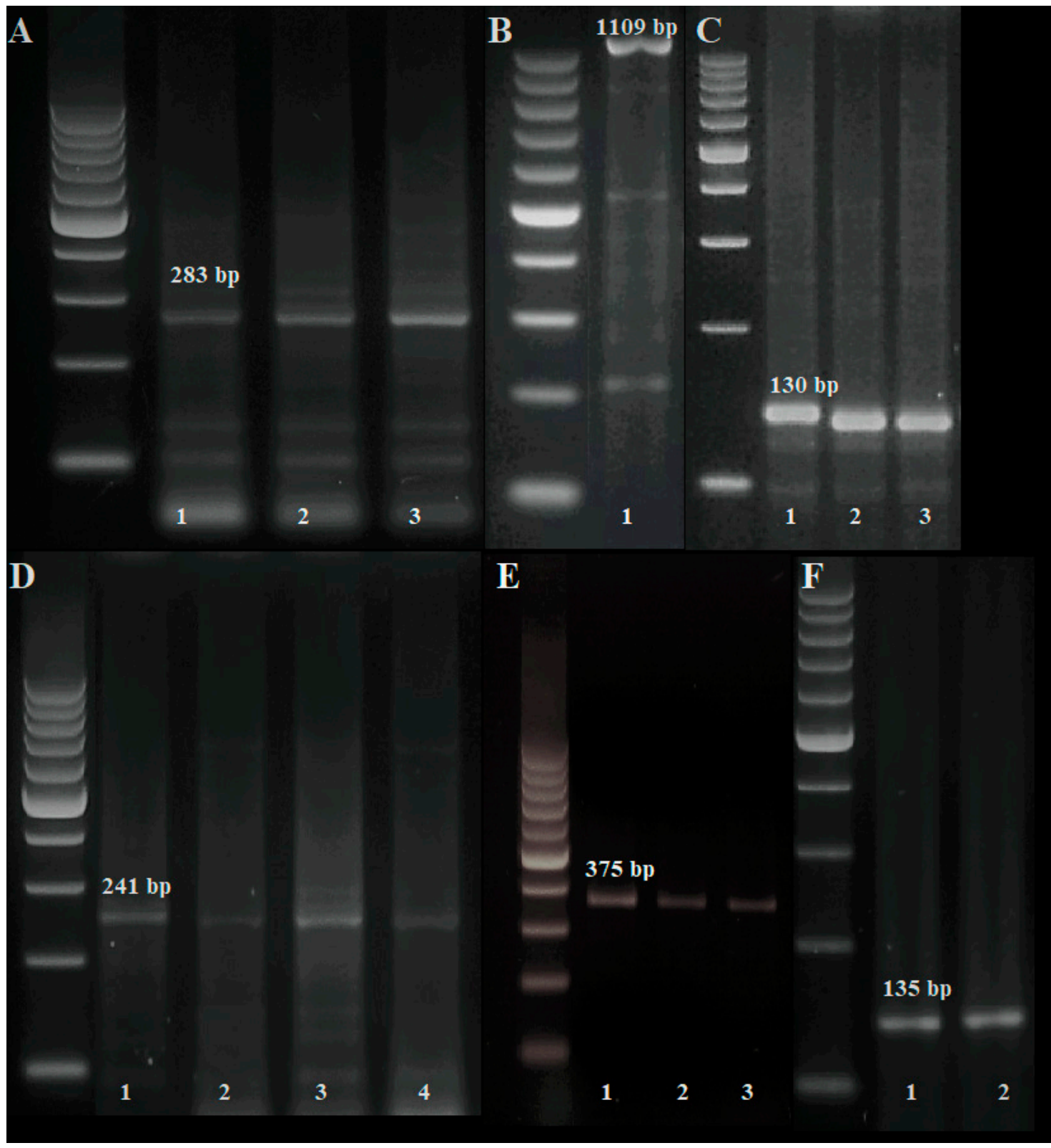

Figure 4. Identification of $P m$ gene markers in exemplary genotypes. Key: A (Pm2a): lane 1-S10, lane 2-cv. Zebra, lane 3-Z $\times$ S11 (breeding line 11), B (Pm3d): lane 1-cv. Zebra, C (Pm4a): lane 1-S11, lane 2-Z $\times$ S11 (breeding line 11), lane 3-Z $\times$ S12 (breeding line 12"), D (Pm4b): lane 1-S10, lane 2-S11, lane 3-Z $\times$ S11 (breeding line 11), lane 4-S10 $\times \mathrm{K}$ (breeding line 20), E (Pm4c): lane 1-S12, lane 2-Z $\times$ S11 (breeding line 11'), lane 3-Z $\times$ S12 (breeding line 12), F (Pm6): lane 1-cv. Kontesa, lane 2-S10 x K (breeding line 20). 


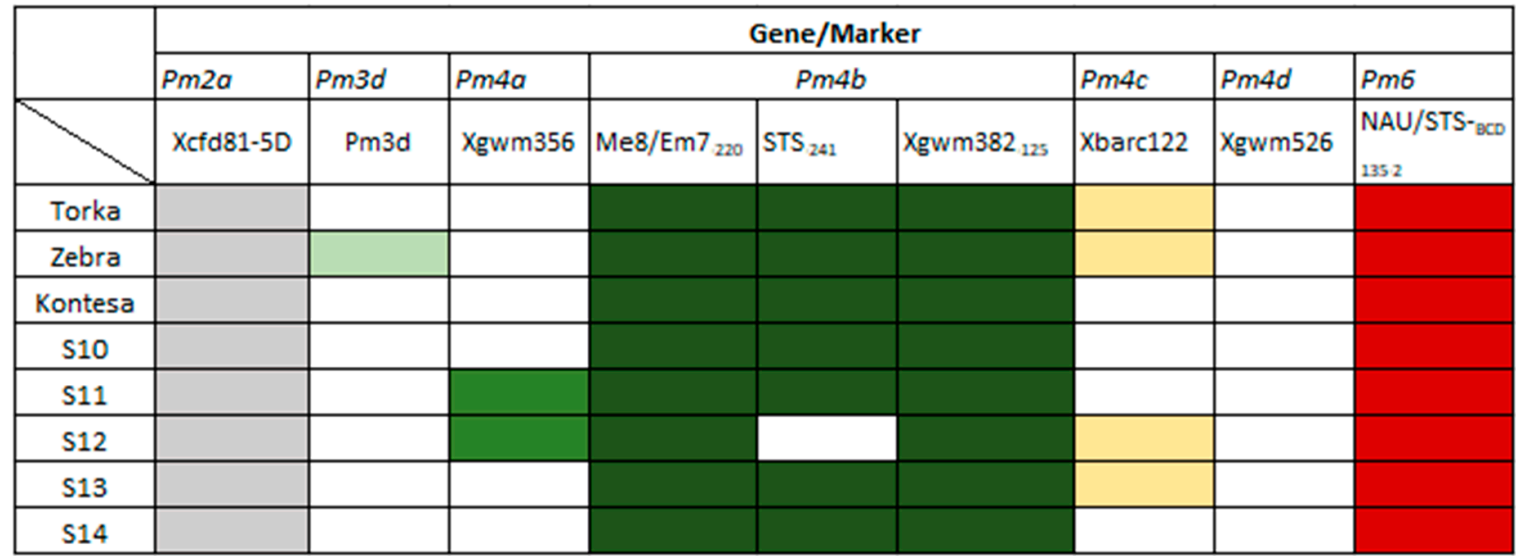

Figure 5. Identification of gene markers associated with wheat resistance to B. graminis $\mathrm{f}$. sp. tritici in bread wheat cultivars and five spelt lines as the parental forms of bread wheat-spelt breeding lines.

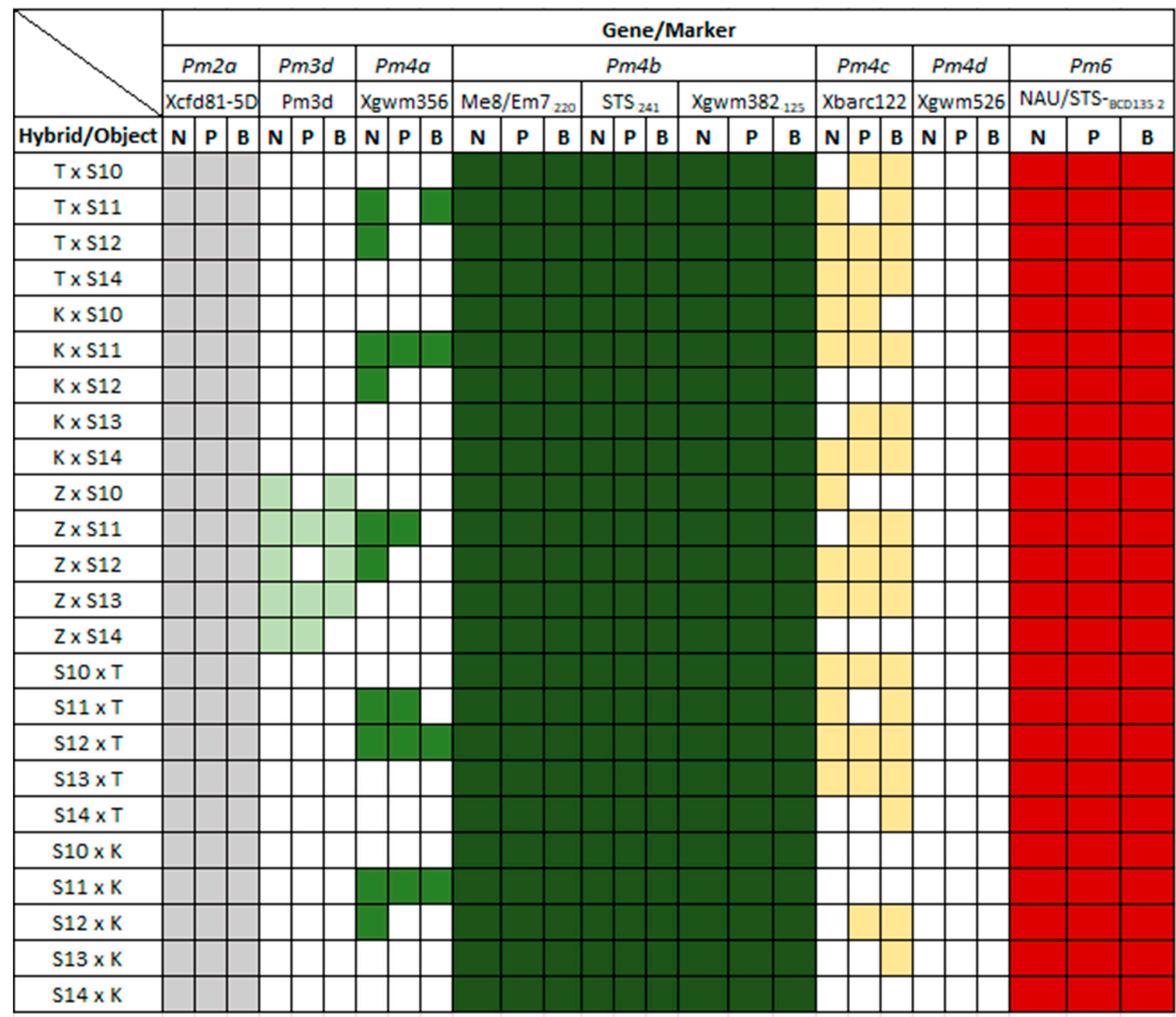

Figure 6. Identification of gene markers associated with wheat resistance to B. graminis f. sp. tritici in bread wheat and spelt lines Key: T—cv. Torka, Z-cv. Zebra, K-cv. Kontesa, N-null lines (e.g., $\mathrm{T} \times \mathrm{S} 10$ is abbreviated as 1), $\mathrm{P}$-prim lines (e.g., T x S10' is abbreviated as 1'), B-bis lines (e.g., T x S10" is abbreviated as 1"). 
A PCR product with a size of $283 \mathrm{bp}$ was found in all tested objects, which confirmed the presence of the Pm2a gene marker. Most objects did not harbor the marker for the Pm3d allele, which was identified only in the genome of bread wheat cv. Zebra and in lines where cv. Zebra was the parental form, excluding lines 10', 12' and 14" (Z $\times$ S10, Z $\times$ S12 and Z $\times$ S14, respectively) (Figures 5 and 6). The marker for the Pm4a allele was identified in the genome of spelt lines S11 and S12, and in a large number of lines where S11 and S12 were the parental forms. It should be noted that the presence of the marker for the Pm4a allele was a differentiating factor in the lines derived from a single cross. All parental forms, excluding spelt line S12, harbored all three markers for the Pm4b allele. Line S12 did not contain the STS -241 marker, but the presence of the two remaining markers for the $P m 4 b$ allele suggests that the genome of this spelt line harbors the $P m 4 b$ gene (Figures 5 and 6 ). In the parental forms of the evaluated wheat-spelt lines, the marker for the $P m 4 c$ allele was identified in the genomes of bread wheat cvs. Torka and Zebra, and in spelt lines S12 and S13 (Figure 5). The marker for the $\mathrm{Pm} 4 \mathrm{C}$ allele was also found in most lines derived from the parental forms that harbored this marker. The only exceptions were the lines originating from $\mathrm{K} \times \mathrm{S} 12$ and $\mathrm{Z} \times \mathrm{S} 14$ crosses, where the marker for the $P m 4 c$ allele was not identified despite its presence in the parental genome (Figure 6). The marker for the Pm4c allele was not present in the lines originating from $\mathrm{S} 10 \times \mathrm{K}, \mathrm{S} 11 \times \mathrm{K}$ and $\mathrm{S} 14 \times \mathrm{K}$ crosses. The marker for the Pm6 gene was present in the genomes of all parental forms and in all breeding lines (Figures 5 and 6).

\subsection{Identification of Lr Resistance Genes}

The presence of PCR products with a size of $560 \mathrm{bp}, 550 \mathrm{bp}$, and $719 \mathrm{bp}$, corresponding to Lr1, Lr9 and Lr24 gene markers, respectively, was not confirmed in any parental forms of the analyzed wheat-spelt lines and in any of the lines (Figure 7). Products corresponding to the Lr10 gene marker were identified in bread wheat cv. Kontesa and in spelt lines S12 and S14. The Lr10 gene marker was found in all wheat-spelt lines whose both parental forms harbored the Lr10 gene, as well as in most of the lines derived from bread wheat cv. Kontesa (Figures 7-9). Selected lines originating from crosses between $\mathrm{Z} \times \mathrm{S} 12, \mathrm{Z} \times \mathrm{S} 14, \mathrm{~S} 12 \times \mathrm{T}$, and S14 $\times \mathrm{T}$ also harbored the $\operatorname{Lr} 10$ gene marker. The $\mathrm{Lr} 28$ gene marker was identified in the genome of bread wheat cv. Zebra and spelt line S10 (Figure 7). This marker was identified based on the presence of a product with a size of $570 \mathrm{bp}$, which was found in the lines derived from the above parental forms (Figure 9).

\begin{tabular}{|c|l|l|l|l|l|}
\hline & \multicolumn{5}{|c|}{ Gene/Marker } \\
\hline & Lr1 & Lr9 & Lr10 & Lr24 & Lr28 \\
\hline & PTAG621 & SCS5 $_{550}$ & Lr10 & SCS73 $_{719}$ & SCS421 $_{570}$ \\
\hline Torka & & & & & \\
\hline Zebra & & & & & \\
\hline Kontesa & & & & & \\
\hline S10 & & & & & \\
\hline S11 & & & & & \\
\hline S12 & & & & & \\
\hline S13 & & & & & \\
\hline S14 & & & & & \\
\hline
\end{tabular}

Figure 7. Identification of gene markers associated with wheat resistance to $P$. triticina in bread wheat cultivars and five spelt as the parental forms of bread wheat-spelt breeding lines. 


\begin{tabular}{|c|c|c|c|c|c|c|c|c|c|c|c|c|c|c|c|}
\hline & \multicolumn{15}{|c|}{ Gene/Marker } \\
\hline & \multicolumn{3}{|c|}{ Lr1 } & \multicolumn{3}{|c|}{$\operatorname{Lrg}$} & \multicolumn{3}{|c|}{$\operatorname{Lr} 10$} & \multicolumn{3}{|c|}{ Lr24 } & \multicolumn{3}{|c|}{$\operatorname{Lr} 28$} \\
\hline & \multicolumn{3}{|c|}{ pTAG621 } & \multicolumn{3}{|c|}{$\mathrm{SCSS}_{550}$} & \multicolumn{3}{|c|}{ Lr10 } & \multicolumn{3}{|c|}{$\operatorname{SCS}_{7319}$} & \multicolumn{3}{|c|}{$\operatorname{SCS} 421_{570}$} \\
\hline Hybrid/Object & $\mathbf{N}$ & $\mathbf{P}$ & B & $\mathbf{N}$ & $\mathbf{P}$ & B & $\mathbf{N}$ & $\mathbf{P}$ & B & $\mathbf{N}$ & $\mathbf{P}$ & B & $\mathbf{N}$ & $\mathbf{P}$ & B \\
\hline $\mathrm{T} \times \mathrm{S} 10$ & & & & & & & & & & & & & & & \\
\hline $\mathrm{T} \times \mathrm{S} 11$ & & & & & & & & & & & & & & & \\
\hline $\mathrm{T} \times \mathrm{S} 12$ & & & & & & & & & & & & & & & \\
\hline $\mathrm{T} \times \mathrm{S} 14$ & & & & & & & & & & & & & & & \\
\hline $\mathrm{K} \times \mathrm{S} 10$ & & & & & & & & & & & & & & & \\
\hline $\mathrm{K} \times \mathrm{S} 11$ & & & & & & & & & & & & & & & \\
\hline $\mathrm{K} \times \mathrm{S} 12$ & & & & & & & & & & & & & & & \\
\hline $\mathrm{K} \times \mathrm{S} 13$ & & & & & & & & & & & & & & & \\
\hline $\mathrm{K} \times \mathrm{S} 14$ & & & & & & & & & & & & & & & \\
\hline$Z \times S 10$ & & & & & & & & & & & & & & & \\
\hline $\mathrm{Z} \times \mathrm{S} 11$ & & & & & & & & & & & & & & & \\
\hline $\mathrm{Z} \times \mathrm{S} 12$ & & & & & & & & & & & & & & & \\
\hline $\mathrm{Z} \times \mathrm{S} 13$ & & & & & & & & & & & & & & & \\
\hline $\mathrm{Z} \times \mathrm{S} 14$ & & & & & & & & & & & & & & & \\
\hline $\mathrm{S} 10 \times \mathrm{T}$ & & & & & & & & & & & & & & & \\
\hline $\mathrm{S} 11 \times \mathrm{T}$ & & & & & & & & & & & & & & & \\
\hline $\mathrm{S} 12 \times \mathrm{T}$ & & & & & & & & & & & & & & & \\
\hline $\mathrm{S} 13 \times \mathrm{T}$ & & & & & & & & & & & & & & & \\
\hline $\mathrm{S} 14 \times \mathrm{T}$ & & & & & & & & & & & & & & & \\
\hline $\mathrm{S} 10 \times \mathrm{K}$ & & & & & & & & & & & & & & & \\
\hline S11 $\times \mathrm{K}$ & & & & & & & & & & & & & & & \\
\hline $\mathrm{S} 12 \times \mathrm{K}$ & & & & & & & & & & & & & & & \\
\hline $\mathrm{S} 13 \times \mathrm{K}$ & & & & & & & & & & & & & & & \\
\hline S14 $\times$ K & & & & & & & & & & & & & & & \\
\hline
\end{tabular}

Figure 8. Identification of gene markers associated with wheat resistance to $P$. triticina in bread wheat and spelt lines Key: T-cv. Torka, Z-cv. Zebra, K-cv. Kontesa, N-null lines (e.g., T $\times$ S10 is abbreviated as 1 ), $\mathrm{P}$-prim lines (e.g., $\mathrm{T} \times \mathrm{S} 10^{\prime}$ is abbreviated as $1^{\prime}$ ), $\mathrm{B}$ - bis lines (e.g., $\mathrm{T} \times \mathrm{S} 10^{\prime \prime}$ is abbreviated as $\left.1^{\prime \prime}\right)$. 


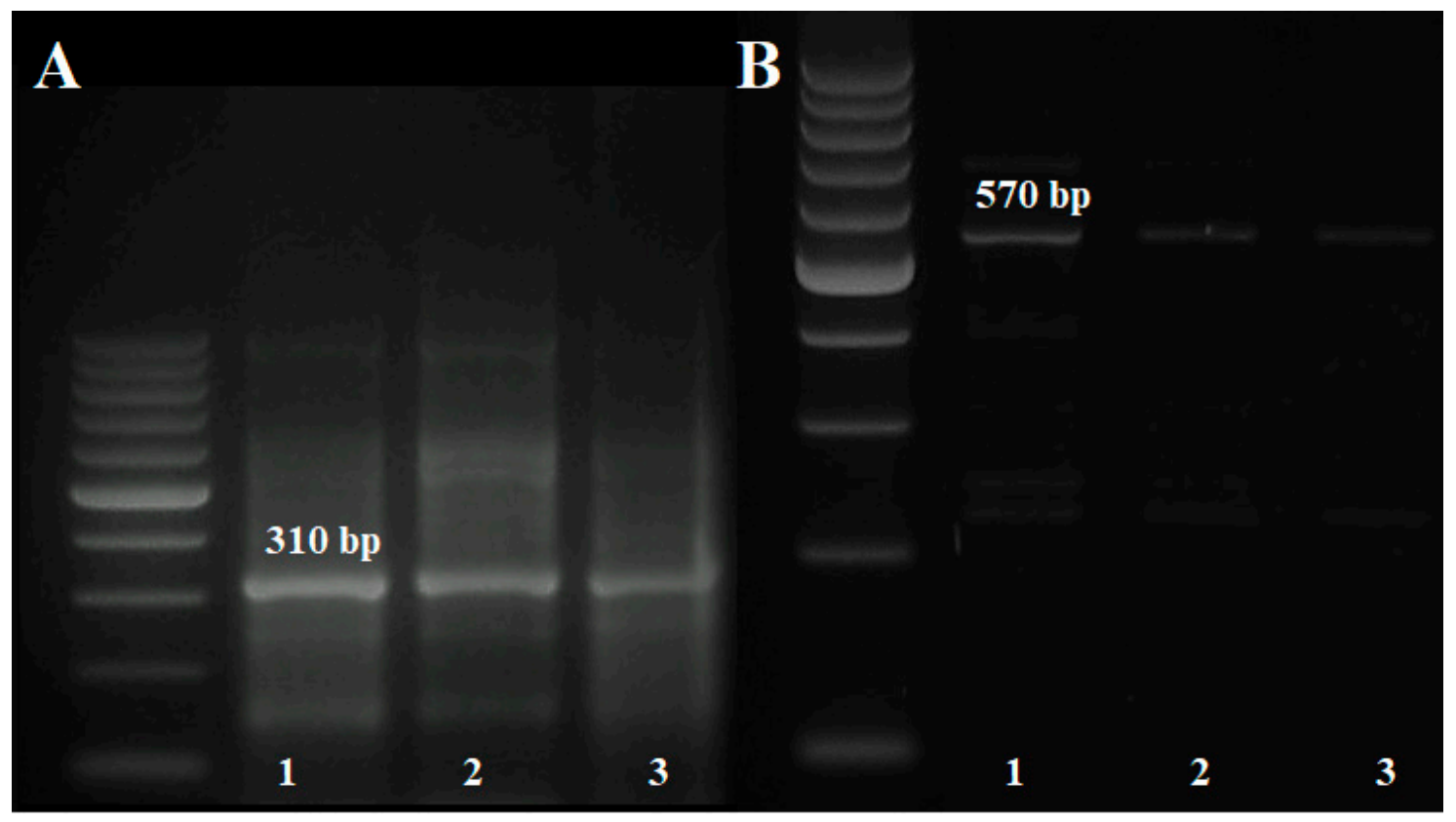

Figure 9. Identification of $L r$ gene markers in exemplary genotypes. Key: $\mathrm{T}-\mathrm{cv}$. Torka, Z-cv. Zebra, $\mathrm{K}-\mathrm{cv}$. Kontesa, (A) (Lr10): lane 1-cv. Kontesa, lane 2-S12, lane 3-K $\times$ S10 (breeding line 5); (B) (Lr28): lane 1-cv. Zebra, lane 2-S10, lane 3-Z $\times$ S12 (breeding line 12).

\section{Discussion}

In this experiment, bread wheat cv. Zebra and spelt line S12 harbored a higher number of markers for genes/alleles encoding resistance to powdery mildew than other parental forms of the analyzed wheat-spelt lines. The marker linked to the $P m 2 a$ allele was present in each object, and its frequency was also high in the bread wheat cultivars examined by Kowalczyk et al. [41]. In the present study, the Pm2 $a$ allele was identified in all parental spelt lines, which suggests that this allele could be widely distributed in spelt populations. However, further research involving a larger number of genotypes is required to validate this observation. According to Li et al. [19], the Pm3d allele is gradually disappearing from bread wheat populations. The cited authors did not identify the marker for the Pm3d allele in molecular analyses of more than 2500 accessions from 85 countries. In the current study, the frequency of the Pm3d allele was also low in the parental forms of the analyzed wheat-spelt lines.

In Poland, the percentage of $B$. graminis f. sp. tritici isolates virulent to the $P m 4 a$ allele was high $(>50 \%)$ already in the first years of the 21st century [42]. The absence of the marker for the Pm4a allele in the analyzed bread wheat cultivars suggests that this gene had been gradually withdrawn from breeding programs. All of the evaluated lines and their parental forms contained at least two markers for the $P m 4 b$ allele. The majority of $B g t$ isolates in the world is not virulent to this allele [21]. These findings point to cyclic changes in the population of $B g t$ isolates. In the early years of the $21^{\text {st }}$ century, Bgt isolates in Poland were highly virulent to cultivars harboring the $P m 4 b$ allele [42]. However, the structure of $B g t$ isolates has not been researched extensively in Poland. The virulence structure of B. graminis f. sp. tritici isolates from triticale was investigated by Czembor et al. [43]. Previous reports had revealed that $B$. graminis $\mathrm{f}$. sp. tritici expanded its host range from wheat to the closely related triticale [44], which suggests that the pathogen's virulence structure in wheat populations continues to change. Kowalczyk et al. [45] demonstrated that triticale and bread wheat hybrids containing the $P m 4 b$ allele were resistant to Bgt isolates in Poland, which indicates that this allele plays an important role in resistance breeding. The third allele of the $P m 4$ gene $-P m 4 c$ (previously identified as $P m 23$ )—is responsible for broad-spectrum resistance to $B g t$ isolates [46]. In this study, the $P m 4 c$ allele was identified in bread wheat cvs. Torka and Zebra, in spelt lines S12 and S13, and in the genomes of many lines derived from at least one parental form harboring this allele. The presence of several 
alleles of a given resistance gene in one breeding line or cultivar can significantly expand its resistance spectrum [14]. Therefore, the lines derived from the crosses between $\mathrm{Z} \times \mathrm{S} 11$ and $\mathrm{Z} \times \mathrm{S} 12$, containing a higher number of markers for $P m 4$ alleles, should theoretically be more resistant to $B$. graminis $\mathrm{f}$. sp. tritici under field conditions, which was confirmed by the present experiment. The marker for the Pm6 gene was identified in all tested objects, which could be attributed to the fact that this gene has been widely used in breeding programs since the 1980s [47,48].

Zebra was the only bread wheat cultivar that contained the marker for the Pm3d gene, and it also harbored the markers for the $P m 2 a$ allele, $P m 4 b-4 c$ alleles, and the $P m 6$ gene. There is a general scarcity of research of the structure of genes conditioning resistance to Bgt in spelt. Longin et al. [49] reported that spelt was characterized by similar or even higher susceptibility to B. graminis $\mathrm{f}$. $\mathrm{sp}$. tritici infections relative to bread wheat. In view of the above findings, the spelt lines (S10-S14) could constitute valuable material for resistance breeding because none of them displayed symptoms of $B$. graminis $f$. sp. tritici infection during the experiment, or the observed symptoms were mild. The genomes of these lines harbored the markers linked to genes and alleles encoding resistance to powdery mildew: Pm2a, $P m 4 a, P m 4 b, P m 4 c$, and $P m 6$. Line $S 12$ emerged as an interesting genetic resource due to the presence of markers for $P m 2 a, P m 4 a-4 c$, and $P m 6$.

Lines $11^{\prime}(\mathrm{Z} \times \mathrm{S} 11)$ and line $12(\mathrm{Z} \times \mathrm{S} 12)$ appear to be particularly valuable sources of genetic resistance to $B$. graminis f. sp. tritici because they harbored the markers for $P m 2 a, P m 3 d, P m 4 a-4 c$ and Pm6. During the entire experiment, none of these lines exhibited symptoms of powdery mildew under field conditions. These observations suggest that a combination of Pm2 (Pm2a allele), Pm4 ( $a-c$ alleles), and $P m 6$ resistance genes should effectively protect wheat-spelt lines against the disease. However, it is also possible that the presence of one particular resistance allele, e.g., $P m 4 a$ or $P m 3 d$, may strongly contribute to field resistance to $B$. graminis $\mathrm{f}$. sp. tritici given that bread wheat-spelt genotypes and their parental forms characterized by the presence of $P m 4 a$ or $P m 3 d$ in their genomes were without infection during field experiment regardless of the gene combination.

In the current study, three of the eight parental forms (cv. Kontesa and spelt lines S12 and S14) harbored the Lr10 marker (seedling resistance gene), whereas the Lr28 marker was identified in cv. Zebra and spelt line S10. The genetic basis of resistance in the studied cereals was limited to only these two genes. The investigated cultivars and breeding lines were also screened for $\operatorname{Lr} 1, \operatorname{Lr} 9$ and Lr24 resistance markers whose effectiveness had been previously demonstrated in both field and greenhouse experiments [50]. However, none of these markers were identified in the studied plant material. The health status assessment conducted in this experiment revealed that spelt was highly resistant to $P$. triticina infections. However, spelt lines S10, S11, and S13 probably contained also other resistance genes than those identified in this study, i.e., $\operatorname{Lr1}, \operatorname{Lr} 9, \operatorname{Lr} 10, \operatorname{Lr} 24$, and $\operatorname{Lr} 28$. Lines $5^{\prime}, 12$ and $20(\mathrm{~K} \times \mathrm{S} 10, \mathrm{Z} \times \mathrm{S} 12$, and S10 $\times \mathrm{K}$, respectively) harbored the markers for both $L r 10$ and $L r 28$. Most importantly, most of these lines do not displayed symptoms of leaf rust or displayed low level of symptoms (breeding line 12) during the two-year study. According to Tomkowiak et al. [51] Lr10 and Lr28 genes encode broad-spectrum resistance to various races of P. triticina in Europe and Central Asia. Leśniowska-Nowak et al. [52] also noted that the Lr10 gene is widely used in Polish breeding programs.

Based on the evaluated combinations of genes encoding resistance to Bgt and $\operatorname{Prt}$, line $12(\mathrm{Z} \times$ S12) emerged as the most promising accessions harboring the highest number of markers for genes and alleles that confer resistance to the infections caused by these pathogens. Line 12 was also highly resistant to powdery mildew and leaf rust under field conditions. In the group of true spelt lines, line S12 appears to be particularly well suited for resistance breeding. Several genes and alleles encoding resistance to powdery mildew (Pm2a, Pm4a, $P m 4 b, P m 4 c$, and $P m 6)$ and leaf rust ( $L r 10)$ were identified in the genome of line S12. This spelt line was also highly resistant to B. graminis $\mathrm{f}$. sp. tritici and P. triticina in both years of the field experiment. Several of the phenotypically homogenous wheat-spelt lines were characterized by high resistance to both pathogens in the field, mostly the lines derived from the crosses between $\mathrm{Z} \times \mathrm{S} 12, \mathrm{Z} \times \mathrm{S} 11, \mathrm{Z} \times \mathrm{S} 14, \mathrm{~S} 11 \times \mathrm{T}$. These objects constitute sources of genetic material for broad-spectrum resistance breeding. This study also demonstrated that the 
genetic sources of resistance to Bgt and Prt were similar in bread wheat and spelt. Therefore, both species can be used to obtain new breeding materials and develop bread wheat cultivars whose genetic composition not only guarantees high nutritional value and desirable technological properties of grain, but also high resistance to fungal pathogens. Triticum spelta can also be a valuable donor of resistance genes that can be used in the pyramidization process. Further research involving a larger number of T. spelta accessions and varieties is needed to identify Bgt and Lrt resistance genes. True spelt lines S10-S14 that had been previously used for simple crossing were selected from a large number of genebank accessions based on their technological suitability (yield, resistance to lodging, resistance to pathogens) because the main aim of research efforts was to obtain simple crosses and lines for further creative breeding. It appears that some of the genebank accessions of T. spelta, characterized by less desirable agronomic and performance traits, may harbor interesting resistance genes. However, further research focusing on resistance breeding is needed to validate this assumption.

Author Contributions: Conceptualization, K.G.-D. and M.W.; methodology, K.G.-D., A.D., and E.S.; software, E.S. and M.W.; validation, K.G.-D., A.D., E.S., and M.W.; formal analysis, K.G.-D. and A.D.; investigation, K.G.-D. and A.D.; resources, M.W. and E.S; data curation, K.G.-D. and M.W.; writing-original draft preparation, K.G.-D. and A.D.; writing-review and editing, K.G.-D. and A.D.; visualization, K.G.-D.; supervision, M.W.; project administration K.G.-D. and M.W.; funding acquisition, K.G.-D. and M.W. All authors have read and agreed to the published version of the manuscript.

Funding: This research was funded by the National Science Centre in Poland (project Preludium 14 [2017/27/N/NZ9/00058]).

Conflicts of Interest: The authors declare no conflict of interest.

\section{References}

1. Maich, R.H.; Steffolani, M.E.; Di Rienzo, J.A.; Leon, A.E. Association between grain yield, grain quality and morpho-physiological traits along ten cycles of recurrent selection in bread wheat (Triticum aestivum L.). Cereal Res. Commun. 2017, 45, 146-153. [CrossRef]

2. Tayyar, S. Variation in grain yield and quality of Romanian bread wheat varieties compared to local varieties in northwestern Turkey. Rom. Biotechnol. Lett. 2010, 15, 5189-5196.

3. Smale, M.; Reynolds, M.P.; Warburton, M.; Skovmand, B.; Trethowan, R.; Singh, R.P.; Ortiz-Monasterio, I.; Crossa, J. Dimensions of diversity in modern spring bread wheat in developing countries from 1965. Crop Sci. 2002, 42, 1766-1779. [CrossRef]

4. Reif, J.C.; Zhang, P.; Dreisigacker, S.; Warburton, M.L.; van Ginkel, M.; Hoisington, D.; Bohn, M.; Melchinger, A.E. Wheat genetic diversity trends during domestication and breeding. Theor. Appl. Genet. 2005, 110, 859-864. [CrossRef]

5. Arzani, A.; Ashraf, M. Cultivated ancient wheats (Triticum spp.): A potential source of health-beneficial food products. Compr. Rev. Food Sci. Food Saf. 2017, 16, 477-488. [CrossRef]

6. Dvorak, J.; Deal, K.R.; Luo, M.C.; You, F.M.; von Borstel, K.; Dehghani, H. The origin of spelt and free-threshing hexaploid wheat. J. Hered. 2012, 103, 426-441. [CrossRef]

7. Wiwart, M.; Perkowski, J.; Jackowiak, H.; Packa, D.; Borusiewicz, A.; Musko, M. Response of some cultivars of spring spelt (Triticum spelta) to Fusarium culmorum infection. Die Bodenkultur 2004, 103, 3.

8. Mankevičienè, A.; Jablonskytè-Raščè, D.; Maikštènienė, S. Occurrence of mycotoxins in spelt and common wheat grain and their products. Food Addit. Contam. Part A 2014, 31, 132-138. [CrossRef]

9. Draz, I.S.; Abou-Elseoud, M.S.; Kamara, A.E.M.; Alaa-Eldein, O.A.E.; El-Bebany, A.F. Screening of wheat genotypes for leaf rust resistance along with grain yield. Ann. Agric. Sci. 2015, 60, 29-39. [CrossRef]

10. Huang, X.Q.; Röder, M.S. Molecular mapping of powdery mildew resistance genes in wheat: A review. Euphytica 2004, 137, 203-223. [CrossRef]

11. Revathi, P.; Tomar, S.M.S.; Singh, N.K. Marker assisted gene pyramiding of leaf rust resistance genes $L r 24$, Lr28 along with stripe rust resistance gene Yr15 in wheat (Triticum aestivum L.). Indian J. Genet. Pl. Br. 2010, 70, 349-354.

12. Jin, Y.; Xu, H.; Ma, P.; Fu, X.; Song, L.; Xu, Y.; Zhang, X.; An, D. Characterization of a new Pm2 allele associated with broad-spectrum powdery mildew resistance in wheat line Subtil. Sci. Rep. 2018, 8, 475. [CrossRef] [PubMed] 
13. Tang, S.; Hu, Y.; Zhong, S.; Luo, P. The Potential Role of Powdery Mildew-Resistance Gene Pm40 in Chinese Wheat-Breeding Programs in the Post-Pm21 Era. Engineering 2018, 4, 500-506. [CrossRef]

14. Ma, P.; Xu, H.; Li, L.; Zhang, H.; Han, G.; Xu, Y.; Fu, X.; Zhang, X.; An, D. Characterization of a new Pm2 allele conferring powdery mildew resistance in the wheat germplasm line FG-1. Front. Plant Sci. 2016, 7, 546. [CrossRef] [PubMed]

15. McIntosh, R.A.; Dubcovsky, J.; Rogers, W.J.; Morris, C.F.; Xia, X.C. Catalogue of gene symbols for wheat. Suppl. Annu. Wheat Newsl. 2017, 53, 1-20.

16. Miedaner, T.; Flath, K. Effectiveness and environmental stability of quantitative powdery mildew (Blumeria graminis) resistance among winter wheat cultivars. Plant Breed. 2007, 126, 553-558. [CrossRef]

17. Tommasini, L.; Yahiaoui, N.; Srichumpa, P.; Keller, B. Development of functional markers specific for seven Pm3 resistance alleles and their validation in the bread wheat gene pool. Theor. Appl. Genet. 2006, 114, 165-175. [CrossRef]

18. Peusha, H.; Enno, T.; Jakobson, I.; Ts[otilde]mbalova, J.; Ingver, A.; Järve, K. Powdery mildew resistance of Nordic spring wheat cultivars grown in Estonia. Acta Agric. Scand. Sect. B-Soil Plant Sci. 2008, 58, $289-296$. [CrossRef]

19. Li, G.; Xu, X.; Bai, G.; Carver, B.F.; Hunger, R.; Bonman, J.M. Identification of novel powdery mildew resistance sources in wheat. Crop Sci. 2016, 56, 1817-1830. [CrossRef]

20. Huang, X.Q.; Hsam, S.L.K.; Zeller, F.J. Identification of powdery mildew resistance genes in common wheat (Triticum aestivum L. em Thell.). IX. Cultivars, land races and breeding lines grown in China. Plant Breed. 1997, 116, 233-238. [CrossRef]

21. Li, N.; Jia, H.; Kong, Z.; Tang, W.; Ding, Y.; Liang, J.; Ma, H.; Ma, Z. Identification and marker-assisted transfer of a new powdery mildew resistance gene at the Pm4 locus in common wheat. Mol. Breed. 2017, 37, 79. [CrossRef]

22. Sharma, C.; Saripalli, G.; Kumar, S.; Gautam, T.; Kumar, A.; Rani, S.; Jain, N.; Prasad, P.; Raghuvanshi, S.; Jain, M.; et al. A study of transcriptome in leaf rust infected bread wheat involving seedling resistance gene Lr28. Funct. Plant Biol. 2018, 45, 1046-1064. [CrossRef] [PubMed]

23. Sapkota, S.; Hao, Y.; Johnson, J.; Lopez, B.; Bland, D.; Chen, Z.; Sutton, S.; Buck, J.; Youmans, J.; Mergoum, M. Genetic mapping of a major gene for leaf rust resistance in soft red winter wheat cultivar AGS 2000. Mol. Breed. 2019, 39, 8. [CrossRef]

24. Pinto da Silva, G.B.; Zanella, C.M.; Martinelli, J.A.; Chaves, M.S.; Hiebert, C.W.; McCallum, B.D.; Boyd, L.A. Quantitative Trait Loci Conferring Leaf Rust Resistance in Hexaploid Wheat. Phytopathology 2018, 108, 1344-1354. [CrossRef]

25. McIntosh, R.A.; Yamazaki, Y.; Dubcovsky, J.; Rogers, W.; Morris, C.; Appels, R.; Xia, X.C. Catalogue of gene symbols for wheat. In Proceedings of the 12th International Wheat Genetics Symposium, Yokohama, Japan, 8-14 September 2013; Ogihara, Y., Takumi, S., Handa, H., Eds.; Springer: Yokohama, Japan, 2015.

26. Goriewa-Duba, K.; Duba, A.; Kwiatek, M.; Wiśniewska, H.; Wachowska, U.; Wiwart, M. Chromosomal distribution of pTa-535, pTa-86, pTa-713, 35S rDNA repetitive sequences in interspecific hexaploid hybrids of common wheat (Triticum aestivum L.) and spelt (Triticum spelta L.). PLoS ONE 2018, 13, e0192862. [CrossRef] [PubMed]

27. List of Agriculture Cultivars Research Center for Cultivar Testing; COBORU: Słupia Wielka, Poland, 2008.

28. Suchowilska, E.; Wiwart, M.; Krska, R.; Kandler, W. Do Triticum aestivum L. and Triticum spelta L. Hybrids Constitute a Promising Source Material for Quality Breeding of New Wheat Varieties? Agronomy 2020, 10, 43. [CrossRef]

29. Witzenberger, A.; Hack, H. Explanations of the BBCH decimal code for the growth stages of cereals-with illustrations. Gesunde Pflanzen 1990, 42, 308-321.

30. Lancashire, P.D.; Bleiholder, H.; Boom, T.V.D.; Langelüddeke, P.; Stauss, R.; WEBER, E.; Witzenberger, A. A uniform decimal code for growth stages of crops and weeds. Ann. Appl. Biol. 1991, 119, 561-601. [CrossRef]

31. EPPO. European and mediterranean plant protection organization. Guideline for the efficacy evaluation of fungicides, foliar diseases of cereals Bulletin. Oepp/Eppo 1998, 28, 279-290.

32. Qiu, Y.; Sun, X.; Zhou, R.; Kong, X.; Zhang, S.; Jia, J. Identification of microsatellite markers linked to powdery mildew resistance gene Pm2 in wheat. Cereal Res. Commun. 2006, 34, 1267-1273. [CrossRef]

33. Röder, M.S.; Korzun, V.; Wendehake, K.; Plaschke, J.; Tixier, M.H.; Leroy, P.; Ganal, M.W. A microsatellite map of wheat. Genetics 1998, 149, 2007-2023. [PubMed] 
34. Ji, J.; Qin, B.; Wang, H.; Cao, A.; Wang, S.; Chen, P.; Zhuang, L.; Du, Y.; Liu, D.; Wang, X. STS markers for powdery mildew resistance gene Pm6 in wheat. Euphytica 2008, 163, 159-165. [CrossRef]

35. Song, Q.J.; Shi, J.R.; Singh, S.; Fickus, E.W.; Costa, J.M.; Lewis, J.; Gill, B.S.; Ward, R.; Cregan, P.B. Development and mapping of microsatellite (SSR) markers in wheat. Theor. Appl. Genet. 2005, 110, 550-560. [CrossRef] [PubMed]

36. Feuillet, C.; Messmer, M.; Schachermayr, G.; Keller, B. Genetic and physical characterization of the LR1 leaf rust resistance locus in wheat (Triticum aestivum L.). Mol. Gen. Genet. MGG 1995, 248, 553-562. [CrossRef]

37. Sohail, Y. Molecular Assessment of Puccinia triticina and Available Wheat Genetic Resources to Combat Leaf Rust in Pakistan. Doctoral Dissertation, Quaid-I-Azam University Islamabad Pakistan, Islamabad, Pakistan, 2015.

38. Schachermayr, G.; Feuillet, C.; Keller, B. Molecular markers for the detection of the wheat leaf rust resistance gene Lr10 in diverse genetic backgrounds. Mol. Breed. 1997, 3, 65-74. [CrossRef]

39. Gupta, S.K.; Charpe, A.; Koul, S.; Prabhu, K.V.; Haq, Q.M.R. Development and validation of molecular markers linked to an Aegilops umbellulata-derived leaf-rust-resistance gene, Lr9, for marker-assisted selection in bread wheat. Genome 2005, 48, 823-830. [CrossRef]

40. Cherukuri, D.P.; Gupta, S.K.; Charpe, A.; Koul, S.; Prabhu, K.V.; Singh, R.B.; Haq, Q.M.R. Molecular mapping of Aegilops speltoides derived leaf rust resistance gene Lr28 in wheat. Euphytica 2005, 143, 19-26. [CrossRef]

41. Kowalczyk, K.; Hsam, S.L.; Zeller, F.J. Identification of powdery mildew resistance genes in common wheat (Triticum aestivum L. em. Thell.). XI. Cultivars grown in Poland. J. Appl. Genet. 1998, 3, 225-236.

42. Svec, M.; Szunics, L.; Miklovicova, M.; Slovakova, T.; Tisova, V.; Hauptvogel, P. Identification of genes for resistance to wheat powdery mildew in Hungarian, Polish and Slovak wheat cultivars. Plant Prot. Sci. -Prague 2002, 38, 64-72. [CrossRef]

43. Czembor, H.J.; Domeradzka, O.; Czembor, J.H.; Mańkowski, D.R. Virulence structure of the powdery mildew (Blumeria graminis) population occurring on triticale (x Triticosecale) in Poland. J. Phytopathol. 2014, 162, 499-512. [CrossRef]

44. Walker, A.S.; Bouguennec, A.; Confais, J.; Morgant, G.; Leroux, P. Evidence of host-range expansion from new powdery mildew (Blumeria graminis) infections of triticale $(\times$ Triticosecale) in France. Plant Pathol. 2011, 60, 207-220. [CrossRef]

45. Kowalczyk, K.; Gruszecka, D.; Nowak, M.; Leśniowska-Nowak, J. Resistance of triticale hybrids with Pm4b and Pm6 genes to powdery mildew. Acta Biol. Ser. Bot. 2011, 53, 57-62. [CrossRef]

46. Zhou, R.; Zhu, Z.; Kong, X.; Huo, N.; Tian, Q.; Li, P.; Jin, C.; Dong, J.; Jia, J. Development of wheat near-isogenic lines for powdery mildew resistance. Theor. Appl. Genet. 2005, 110, 640-648. [CrossRef] [PubMed]

47. Bennett, F.G. Resistance to powdery mildew in wheat: A review of its use in agriculture and breeding programmes. Plant Pathol. 1984, 33, 279-300. [CrossRef]

48. Shah, L.; Rehman, S.; Ali, A.; Yahya, M.; Riaz, M.W.; Si, H.; Ma, C.; Lu, J. Genes responsible for powdery mildew resistance and improvement in wheat using molecular marker-assisted selection. J. Plant Dis. Prot. 2018, 125, 145-158. [CrossRef]

49. Longin, C.F.H.; Würschum, T. Genetic variability, heritability and correlation among agronomic and disease resistance traits in a diversity panel and elite breeding material of spelt wheat. Plant Breed. 2014, 133, 459-464. [CrossRef]

50. Nocente, F.; Gazza, L.; Pasquini, M. Evaluation of leaf rust resistance genes Lr1, Lr9, Lr24, Lr47 and their introgression into common wheat cultivars by marker-assisted selection. Euphytica 2007, 155, 329-336. [CrossRef]

51. Tomkowiak, A.; Kurasiak-Popowska, D.; Mikołajczyk, S.; Weigt, D.; Niemann, J.; Kiel, A.; Lisewska, A.; Nawracała, J.; Matysik, P.; Rokicki, M.; et al. Identyfikacja genu Lr19 warunkującego odporność na rdzę brunatna powodowana przez Puccinia recondita f. sp. tritici w zagranicznych odmianach pszenicy ozimej Triticum aestivum L. Prog. Plant Prot. 2016, 56, 318-323. [CrossRef]

52. Leśniowska-Nowak, J.; Grądzielewska, A.; Majek, M. Identification of the gene resistant to leaf rust in selected European wheat cultivars and Multiplex PCR development. Ann. Univ. Mariae Curie-Skłodowska Sect. E Agric. 2013, 68, 20-28. [CrossRef]

(C) 2020 by the authors. Licensee MDPI, Basel, Switzerland. This article is an open access article distributed under the terms and conditions of the Creative Commons Attribution (CC BY) license (http://creativecommons.org/licenses/by/4.0/). 